\title{
Role of Membrane Rafts in Viral Infection
}

\author{
Tadanobu Takahashi and Takashi Suzuki*
}

\author{
Department of Biochemistry, School of Pharmaceutical Sciences, University of Shizuoka, and Global COE Program for \\ Innovation in Human Health Sciences, Shizuoka 422-8526, Japan
}

\begin{abstract}
Membrane rafts are small (10-200 nm), heterogeneous, highly dynamic, sterol- and sphingolipid-enriched domains that compartmentalize cellular processes. Many studies have established that membrane rafts play an important role in the process of virus infection cycle and virus-associated diseases. It is well known that many viral components or virus receptors are concentrated in the lipid microdomains. Viruses are divided into four main classes, nonenveloped RNA virus, enveloped RNA virus, nonenveloped DNA virus, and enveloped DNA virus. General virus infection cycle is also classified into two sections, the early stage (entry) and the late stage (assembly and budding of virion). Caveola-dependent endocytosis has been investigated mostly by analysis of cell entry of the SV40 representative of polyomaviruses. Thus, the study of membrane rafts has been partially advanced by virological researches. Membrane rafts also act as a scaffold of many cellular signal transductions. Involvement of membrane rafts in many virus-associated diseases is often responsible for up- or down-regulation of cellular signal transductions. What is the role of membrane rafts in virus replications? Viruses do not necessarily require and probably utilize membrane rafts for more efficiency in virus entry, viral genome replication, high-infective virion production, and cellular signaling activation toward advantageous virus replication. In this review, we described the involvement of membrane rafts in the virus life cycle and virus-associated diseases.
\end{abstract}

\section{INTRODUCTION}

Lipid rafts, membrane microdomains enriched in cholesterol and sphingolipids (representatives of which are GM1 and Gb3Cer), were defined in the Keystone Symposium on Lipid Rafts and Cell Function (March 23-28, 2006 in Steamboat Springs, CO) as follows: "Membrane rafts are small $(10-200 \mathrm{~nm})$, heterogeneous, highly dynamic, sterol- and sphingolipid-enriched domains that compartmentalize cellular processes. Small rafts can sometimes be stabilized to form larger platforms through protein-protein and protein-lipid interactions." This definition led to the term "lipid raft" being discarded in favor of the term "membrane raft." The term "membrane raft" underlies the concept that both proteins and lipids, rather than solely lipid-driven interactions, contribute to the genesis of these membrane microdomains. Relationships between virus infection mechanisms and membrane rafts had often been studied on complexes with caveolae [1,2]. The caveola is a cholesterol/sphingolipid-rich small pit, depression, or invagination, which is a site on the cell surface that provides a place for proteins and lipids to interact and generate signals. Is the caveola related to the membrane raft? In the symposium, a range of 10-200 $\mathrm{nm}$ was adopted as the size of membrane rafts. Because the $200 \mathrm{~nm}$ upper limit was set to include the surface area of the caveola, it was unanimously accepted as the membrane raft family [3]. Therefore, in this review, membrane rafts include caveolae.

\footnotetext{
*Address correspondence to this author at the Department of Biochemistry, University of Shizuoka, School of Pharmaceutical Sciences and Global COE Program for Innovation in Human Health Sciences, 52-1 Yada Shizuoka 422-8526, Japan; Tel: 81-54-264-5725; Fax: 81-54-264-5725;

E-mail: suzukit@u-shizuoka-ken.ac.jp
}

Many studies have established that membrane rafts play an important role in the process of virus entry, assembly, and budding. These studies have demonstrated the localization of viral structural proteins in membrane rafts and the effects of raft-disrupting agents (mainly removing reagents and synthesis inhibitors of cholesterol) in the replication processes of several viruses, including retroviruses (Retroviridae), RNA viruses (classified into Picornaviridae, Caliciviridae, Astroviridae, Reoviridae, Flaviviridae, Togaviridae, Bunyaviridae, Coronaviridae, Rhabdoviridae, Arenaviridae, Filoviridae, Orthomyxoviridae, and Paramyxoviridae), and DNA viruses (classified into Parvoviridae, Papovaviridae, Adenoviridae, Herpesviridae, Hepadnaviridae, and Poxviridae). First of all, viruses attach to specific receptors on the host cell surfaces. Initial viral infection arises via endocytosis or by injection of viral proteins and genes directly into the cytoplasm, by fusion of the viral envelope or by destruction of the viral capsids. Transcription and replication of DNA viruses except poxviruses generally take place inside the nucleus, whereas those of RNA viruses except influenza viruses occur in the cytoplasm (Fig. 1). Once the progeny viral components have been produced, they are transferred to some organelles or the plasma membrane, where formation of the progeny virus is processed by assembly and/or budding. Based on the viral outer structure, virus particles are classified into enveloped viruses (Herpesviridae, Hepadnaviridae, Poxviridae, Flaviviridae, Togaviridae, Retroviridae, Bunyaviridae, Coronaviridae, Rhabdoviridae, Arenaviridae, Filoviridae, Orthomyxoviridae, and Paramyxoviridae) and nonenveloped viruses (Parvoviridae, Papovaviridae, Adenoviridae, Picornaviridae, Caliciviridae, Astroviridae, and Reoviridae). The envelope of virus particles is acquired from the plasma membrane of the cell surface, Golgi apparatus, or endoplasmic reticulum (ER) by budding. The envelope 


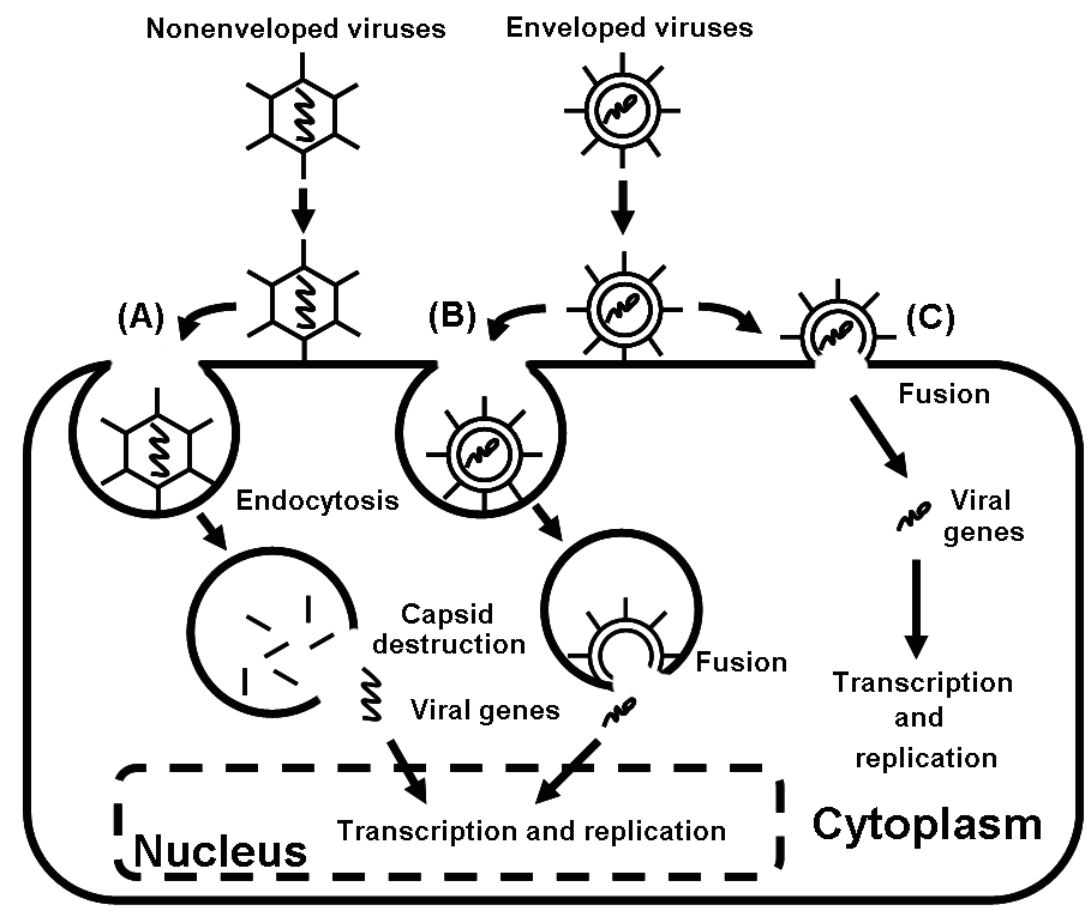

Fig. (1). Entry processes of enveloped and nonenveloped viruses into cells. (A) Endocytosis and capsid degradation of nonenveloped viruses such as Papovaviridae and Adenoviridae family. (B) Endocytosis and membrane fusion with endosomes of enveloped viruses such as Orthomyxoviridae, Togaviridae, and Rhabdoviridae family. (C) Direct membrane fusion with cell surface of enveloped viruses such as Paramyxoviridae family. Herpesviridae family enters cells through either (B) or (C) pathway.

constructs a lipid bilayer derived from the host cell membrane and is buried by viral surface proteins. Nonenveloped viruses are generally assembled in the cytoplasm or nucleus and burst into the extracellular environment by cell death (Fig. 2). This review discusses recent knowledge of the function of membrane rafts in the replication and disease of viruses.

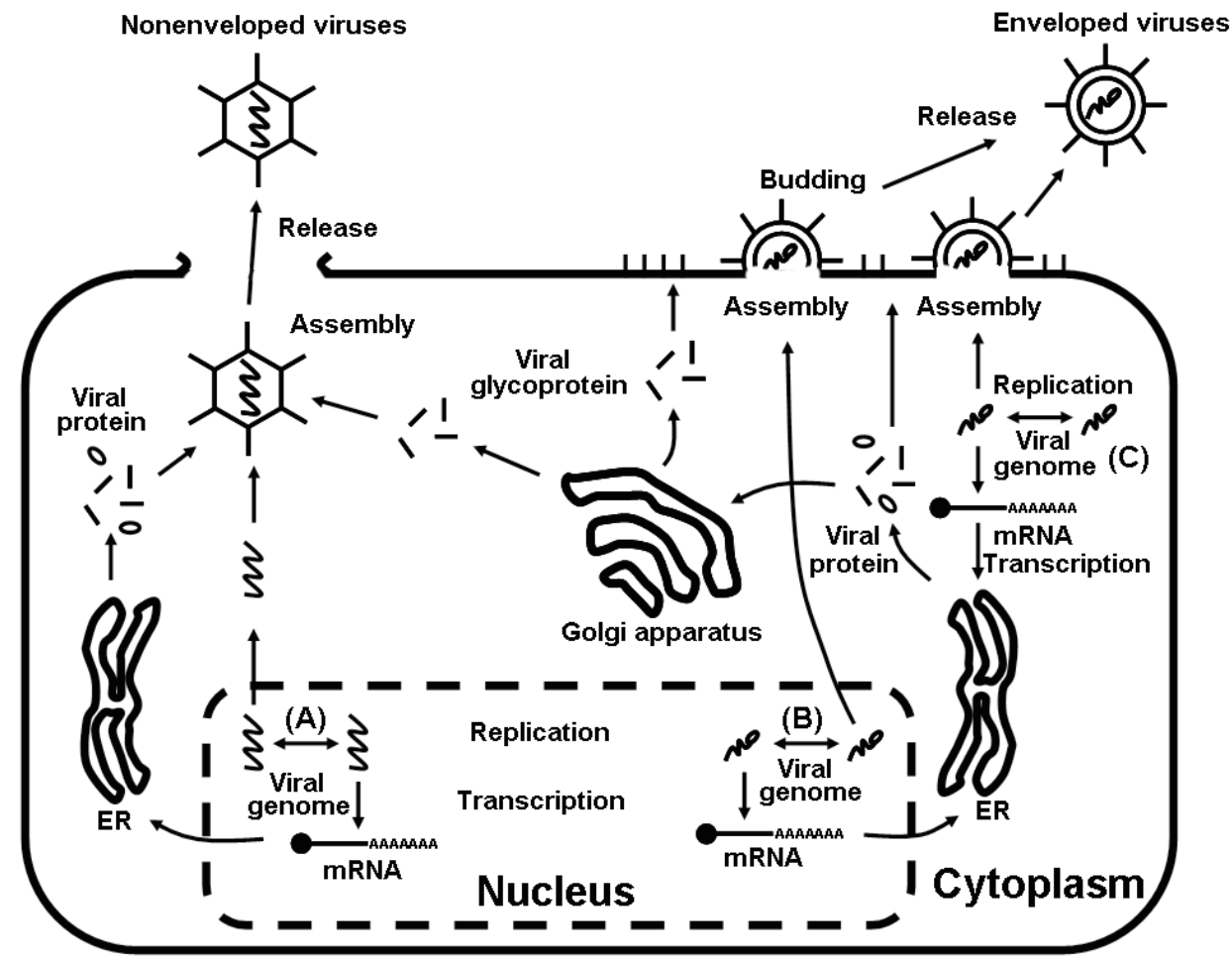

Fig. (2). Assembly and budding of enveloped and nonenveloped viruses. (A) Genes of nonenveloped DNA viruses such as Papovaviridae and Adenoviridae family. (B) Genes of enveloped RNA viruses such as Orthomyxoviridae family and enveloped DNA viruses such as Herpesviridae family. (C) Genes of enveloped RNA viruses such as Paramyxoviridae family. 


\section{ROLE OF MEMBRANE RAFTS IN VIRUS ENTRY}

The involvement of membrane rafts in virus entry has been evaluated by the inhibitory effect of virus infection on disruption of membrane rafts by cholesterol-removing reagents such as methyl- $\beta$-cyclodextrin or cholesterol synthesis inhibitors such as lovastatin for pharmacological methods. In the condition of cholesterol depletion, addition of exogenous cholesterol rescued virus infection without affecting virus binding to the cellular receptors. Biochemical approaches have also confirmed that viral proteins and viral cellular receptors in the early stage of virus infection are detected together in the detergent-insoluble fraction or raftmarkers such as caveolin-1, flotillin, and GM1. Caveoladependent endocytosis on virus entry has also been investigated by inhibition of caveola formation using RNA interference (RNAi) and dominant-negative protein expression for normal caveolin-1 knockdown.

The role of membrane rafts in entry of nonenveloped viruses has been investigated for simian virus 40 (SV40; Papovaviridae) [4-12], BK virus (Papovaviridae) [13-15], JC virus (Papovaviridae) [16], bovine papillomavirus (Papovaviridae) [17], human papillomavirus (HPV; Papovaviridae) [18-26], rotavirus (Reoviridae) [27-29], echovirus type 1 [30] and 11 (Picornaviridae) [31-35], enterovirus (Picornaviridae) [31], rhinovirus (Picornaviridae) [36], Coxsackievirus A9 and B4 (CAV; Picornaviridae) [3739], and species $\mathrm{C}$ human adenovirus (HAdV; Adenoviridae) $[40,41]$.

Clathrin-dependent endocytosis is the most wellestablished pathway of viral endocytosis. On the other hand, caveola-dependent endocytosis has been investigated mostly by analysis of cell entry of the SV40 representative of polyomaviruses, which causes cancer in some animals through repression of tumor suppressor p53 [42]. SV40 binds to major histocompatibility complex class I (MHC-I) on the cell surface. Then, caveola and caveolin-1 are recruited to the association site of SV40 with MHC-I [43, 44]. After activation of tyrosine kinases, depolymerization of the actin skeleton, formation of actin tails, and accumulation of dynamin around the association site of SV40 [45, 46], caveola incorporates SV40 and is budded from the cellular membrane to the intracellular compartment. Finally, caveola transports viral particles to the ER along cellular microtubules. Although SV40 receptor MHC-I is not localized in membrane rafts, MHC-1 induces association of viral particles with caveola [4-8], or GM1 ganglioside, which is enriched in membrane rafts and known to be one of receptors for SV40 and murine polyoma virus $[10,11]$. Other polyomaviruses, including BK virus and JC virus, have been reported to utilize caveola-mediated endocytosis in virus entry [13-16, 47]. BK virus, which is a causative agent of an infectious complication termed polyomavirusassociated nephropathy in renal transplant recipients, enters cells by slow caveola-mediated endocytosis dependent on $\mathrm{pH}$ in Vero cells and human renal proximal tubular epithelial cells [13-15]. JC virus and bovine papillomavirus are transported to early endosomes and caveolae by clathrindependent endocytosis and then carried by the slow caveoladependent pathway $[16,17]$.

The casual relationship between HPVs and cervical cancer is well established. HPVs have been implicated in other epithelial cancers, including head and neck cancers. Over 100 different HPV types have been identified. Highrisk carcinogenic HPVs were defined as types $16,18,31,33$, $35,39,45,51,52,56,58,59,66$ and 68 . Low-risk HPVs were defined as types $6,11,32,34,40,42,43,44,53,54$, 55, 61, 70, 72, 73, 81, 83, 84, 89 and Pap155. Most often, HPV 16 is a primary etiologic agent for anogenital malignancies, particularly for cervical cancer [48]. Enhancement of HPV 18 gene expression in HPV18harboring Hela cells by treatment with cholesterol treatment has suggested the relationship between HPV infection cycle and membrane rafts [19]. Host cell entry of HPVs except HPV31 is initiated by binding of the virus particles to specifically modified heparan sulfate proteoglycans (HPSGs), most likely syndecans. In addition, $\alpha 6$ integrin as well as laminin 5 have been suggested to function as transient receptors for HPV. Although HSPGs were known to be associated with membrane rafts [49], binding of HPV 33 pseudovirus to HSPGs is followed by delayed caveolaindependent endocytosis [20]. Interestingly, initial infection of HPV 16 or 58, which enter host cells in a half time of $4 \mathrm{~h}$, is involved in clathrin-mediated endocytosis. Entry of HPV 31 to COS-7 cells is related to caveola-mediated endocytosis. These studies have indicated that HPVs use distinct routes of viral entry to host epithelial cells [21]. In human keratinocytes (HKs) as a natural host cell type of HPVs, initial infection of HPV 31, which slowly enters the cells in a half time of approximately $14 \mathrm{~h}$, requires both caveolin-1 and dynamin-2 [24, 25]. Both HPV 16 and 31 require the acidic compartment of the endosomal pathway to promote viral genome uncoating by conformational change in the HPV capsid. As described above, the initial infection of HPV 16 and 33 to HKs requires HPSGs; however, HPV 31 interaction with cell surface HSPGs is not required for infection of HKs. HPV 16 also uses clathrin- and caveolinindependent entry associated with tetraspanins CD63 and CD151 [26]. Complexes of tetraspanins CD63 and CD151 with $\alpha 6$ integrin and laminin via $\beta 4$ palmitoylation form cholesterol-associated microdomains that are distinct from membrane rafts $[50,51]$. HPVs may also use tetraspaninenriched microdomains as an entry platform. The different entry mechanisms of these two types may reflect this distinct binding requirement [25].

Rotaviruses, which cause severe diarrhea in infants and young children, recognize several cell molecules of the epithelial cell surface, including glycolipids, $N$ glycoproteins, $\mathrm{HSC} 70$ protein, and $\alpha_{\mathrm{V}} \beta_{3}$ integrin, that are localized in membrane rafts $[27,28]$.

Echovirus type 1 and a number of enteroviruses, including echovirus type 11, which cause nerve paralysis, cerebral meningitis, respiratory symptoms and anthema, utilize $\alpha_{2} \beta_{1}$ integrin and glycosylphosphatidylinositol (GPI)anchored complement regulatory protein decay-accelerating factor (DAF) on the cell surface as the respective receptor, which induces activation of caveola- and membrane raftdependent endocytosis [30-34]. A recent study has suggested that clustering of $\alpha_{2} \beta_{1}$ integrin with echovirus type 1 defines the unique entry pathway that is p21-activated kinase 1 (Pak1), Rac1, phosphatidylinositol 3-kinase (PI3K), phospholipase C (PLC), and actin dependent but clathrin and caveolin independent and that is able to sort cargo to caveosomes [35]. 
Rhinoviruses, which are the general pathogens of colds and acute respiratory symptoms, utilize ceramide-enriched membrane platforms (CEMP) for viral entry. Rhinoviruses induce microtubule- and microfilament-mediated translocation of acid sphingomyelinase from an intracellular compartment onto the extracellular leaflet of the cell membrane. The enzymatic activity of acid sphingomyelinase converts ceramide from sphingomyelin in the cell membrane and finally forms large CEMP. The significance of CEMP for rhinovirus entry has been demonstrated by genetic and pharmacological inhibition of acid sphingomyelinase [36]. CEMP may serve to cluster rhinovirus receptors, particularly intercellular adhesion molecule-1 (ICAM-1) [52-54], which is a component of membrane rafts [55], for rhinovirus 14 and rhinovirus 16 and LDL receptor family for rhinovirus 2 [36].

CAV-A9 infection is one of the most frequent causes of aseptic meningitis and causes various symptoms such as flaccid paralysis, respiratory disease, and chronic myocarditis. The virus utilizes $\alpha_{\mathrm{v}} \beta_{3}$ integrin as a receptor, glucose-regulated protein 78 (GRP78) as a coreceptor, and accessory molecule MHC-I in the virus entry process. These molecules are concentrated in membrane rafts following virus infection. The Raf/ mitogen-activated protein kinase (MAPK) signaling pathway is activated in lipid rafts upon CAV-A9 infection. The signaling machinery of Raf/MAPK activation after binding of CAV-A9 is unclear [37, 38]. CAV B4 infection causes insulin-dependent diabetes mellitus, also known as type I diabetes, by progressive destruction of pancreatic $\beta$ cells. The virus is colocalized with cellular receptor coxsackie adenovirus receptor protein (CAR) and CD55 within membrane rafts. Internalization of CAV B4 and rapid movement to the Golgi apparatus are independent of clathrin-mediated endocytosis. However, this transport pathway appears to be raft-specific [39].

HAdV, which is a common pathogen of acute respiratory disease and epidemic keratoconjunctivitis, is frequently used as elaborated viral vectors for gene therapy, most of which are derived from serotype 5 viruses. HAdVs generally take advantage of clathrin-coated pit endocytosis. Initial interaction of HAdV with the virus receptor CAR and heparan sulfate glycosaminoglycans [56] is followed by interaction of the RGD motif of the virus with $\alpha_{\mathrm{V}} \beta_{3}, \alpha_{\mathrm{V}} \beta_{5}$, $\alpha_{\mathrm{M}} \beta_{2}$, and $\alpha_{5} \beta_{1}$ integrins, resulting in clathrin-coated pit endocytosis of HAdV in hematopoietic cells. In contrast, mature B cell plasmocytes and Chinese hamster ovary (CHO), CAR-negative cell line, are permissive to infection of HAdV5 [40], HAdV2 and HAdV4 [41], respectively via clathrin-independent, caveola/raft-dependent endocytosis machinery.

In addition to its role in entry of non enveloped the role of membrane rafts in entry of enveloped viruses has been investigated in studies using influenza virus (Orthomyxoviridae) [57-61], human immunodeficiency virus type 1 (HIV-1; Retroviridae) [62-67], human $\mathrm{T}$ lymphotropic virus 1 (HTLV-1; Retroviridae) [68, 69], Ebola virus (Filoviridae) [70], Marburg virus (Filoviridae) [70, 71], Epstein-Barr virus (EBV; herpesviridae) $[72,73]$, herpes simplex virus-1 (HSV-1; herpesviridae) [74] including porcine herpesvirus-1 pseudorabies virus [75], human herpesvirus-6 (HHV-6; Herpesviridae) [76], human herpesvirus-8 (HHV-8; Herpesviridae) [77], vaccinia virus (Poxviridae) [78], coronavirus including severe acute respiratory syndrome coronavirus (SARS-CoV; Coronaviridae) [79-85], West Nile virus (WNV; Flaviviridae) [86], dengue virus (DEN; Flaviviridae) [87-89], Japanese encephalitis virus (JEV; Flaviviridae) [89], human hepatitis C virus (HCV; Flaviviridae) [90, 91], Semliki Forest virus (Togaviridae) [92-95], Sindbis virus (Togaviridae) [95, 96], and lymphocytic choriomeningitis virus (LCMV; Arenaviridae) [97]. The involvement of membrane rafts in infectious particle prion ( $\mathrm{PrP})$ infection has also been investigated [98$101]$.

The majority of enveloped viruses internalize and release viral genes into the intracellular compartment by fusion between the viral envelope and plasma membranes or endosome/lysosome membranes after attachment of the viruses to the receptors or during endocytosis.

Influenza viruses, which are highly transmittable pathogens of severe acute respiratory symptoms in various animals including human beings, internalize into host cells through multiple pathways including clathrin-independent and caveola-independent endocytosis $[58,60,61]$ after binding of the virus to a terminal sialic acid linked to glycoconjugates on the cell surface via a viral surface glycoprotein, hemagglutinin (HA) [102, 103]. After transportation of the virus to late endosomes, low-pHdependent conformation change of HA induces membrane fusion of the viral envelope with the endosomal membrane. Then viral ribonucleoprotein complexes (RNP) including the viral genome are released to the cytoplasm of host cells by proton influx of viral ion channel M2 protein that requires binding with cholesterol $[57,104]$. Similar to the entry process of influenza virus, capsid-like core particles of hepatitis B virus (Hepadnaviridae) are internalized through clathrin-dependent and raft-independent endocytosis [105].

HIV-1, which causes long-term and chronic disease that gradually progresses to acquired immunodeficiency syndrome, binds to CD4 on the cell surface via the viral surface glycoprotein gp120. Conformational change of gp120 by this binding leads to interaction with coreceptors, CXCR4 or CCR5, and a subsequent conformational change of the viral transmembrane glycoprotein gp41 for acquirement of membrane fusion activity [106-108]. Approximately 11 to $18 \%$ of CCR5 in human adenocarcinoma cells, 90 to $95 \%$ of CD4 in H9 leukemic T cells, and 50 to $66 \%$ of CD4 in peripheral blood mononuclear cells (PBMCs) are present in isolated membrane rafts $[109,110]$. On the other hand, CXCR4 in human embryonic kidney 293T cells, H9 leukemic T cells, and PBMCs is almost entirely absent from isolated membrane rafts $[62,110]$. However, a recent study has indicated that CXCR4 clustering in membrane rafts on $293 \mathrm{~T}$ cells (not human glioma NP2 and human rhabdosarcoma TE671), rather than CD4, is the key step for HIV-1 entry [67]. Interactions between CD4 and CCR5, which take place outside membrane rafts, have been also postulated to influence susceptibility to CCR5-tropic HIV entry process [111]. A recent study has shown that CD4 and CCR5 are partitioned to membrane rafts in macrophage and has suggested that cholesterol of macrophage membrane is essential for HIV entry [66]. The crucial answer to these apparently controversial observations will require more 
discussions about the involvement of CD4-coreceptor complexes in membrane raft for receptor binding and entry of HIV-1. Additionally, glycosphingolipids abundantly present in membrane rafts of host cells, such as globotriaosyl ceramide (Gb3Cer), GM3 ganglioside, and galactosylceramide, are involved in interaction with viral glycoproteins and in the viral entry process [112-115]. However, HIV-1 entry into primary human brain microvascular endothelial cells appears to be a raftindependent mechanism involving cell-associated heparan sulfate and chondroitin sulfate proteoglycans [116].

HTLV-1, which is an oncogenic pathogen leading to human adult $\mathrm{T}$ cell leukemia, enters host cells via glucose transporter 1 (GLUT-1) [117], which is targeted to membrane rafts in a state of glucose deprivation [118]. Inhibition of viral entry and syncytium formation by depletion of cholesterol suggests the involvement of membrane rafts in HTLV-1 entry and the fusion process [68, 69].

Ebola virus and Marburg virus are two of the most pathogenic viruses in humans and nonhuman primates, causing severe hemorrhagic fever with mortality rates reaching $90 \%$. These viruses enter host cells via folate receptor- $\alpha(F R \alpha)$ as a viral coreceptor, which is a GPIanchored protein present in rafts [119]. Studies performed using pseudotypes of the viruses have suggested that filoviruses use acidified endosomes for viral entry [120, 121]; however, the viral cell surface receptors and endocytosis pathway remain unknown. Inhibitory effects of a cholesterol-removing reagent and a cholesterol synthesis inhibitor on viral infection have demonstrated the involvement of membrane rafts in filovirus entry [70,71].

EBV is a human herpesvirus that causes infectious mononucleosis and is associated with a variety of human lymphocytic and epithelial neoplasms, including Burkitt's lymphoma and nasopharyngeal carcinoma. EBV recognizes human complement receptor type 2 (CR2), which is also known as CD21, on the cell surface of B lymphocytes [72, 122]. Complexes of CD21 with CD19 and CD81 are located in membrane rafts that require palmitoylation of CD81. Signaling through B cell antigen receptor (BCR) is enhanced due in part to the ability of CD19/CD21/CD81 complex to stabilize BCR in membrane rafts [73].

HSV belonging to the family of alpha-herpes viruses, typical pathogens responsible for mucosal lesions of the mouth and genital organs in humans, binds and enters host cells by a complex process involving the essential viral glycoproteins $\mathrm{B}(\mathrm{gB}), \mathrm{gD}, \mathrm{gH}$, and $\mathrm{gL}$ and multiple cellular molecules including the tumor necrosis factor receptor (TNFR) family [123], nectin-1 or nectin-2 (two members of the immunoglobulin superfamily) [124], paired immunoglobulin-like type 2 receptor (PILR) [125], and particular type of modified HSPGs [126, 127]. Raft associations of TNFR are essential for TNFalpha-mediated NF- $\kappa B$ activation [128]. Raft associations of HSPG are also correlated with the activation of protein kinase $\mathrm{C} \alpha(\mathrm{PKC} \alpha)$ [49]. Binding of HSV-1 gD to cells does not result in association of nectin-1 with rafts before or during HSV-1 infection in several cell lines. However, HSV-1 gB but not $\mathrm{gC}, \mathrm{gD}$, or $\mathrm{gH}$ associates with rafts after virus attachment and during entry. Moreover, treatment with cholesterol- lowering reagents results in inhibition of HSV-1 and pseudorabies virus entry $[74,75]$.

HHV-6 is a beta-herpes virus related to human herpesvirus 7 and human cytomegalovirus and is a human pathogen of emerging clinical significance. Human CD46, a cellular receptor for HHV-6, is not associated with membrane rafts in uninfected cells. However, after virus attachment, CD46 is re-located to rafts. HHV-6 entry is inhibited by cholesterol depletion, while HHV-6 infection is rescued by adding exogenous cholesterol. Membrane rafts appear to be important in the HHV-6 entry process [76].

HHV-8 is the most recently identified member of the family of human gamma-herpes viruses and has been consistently identified in all forms of Kaposi's sarcoma, primary effusion lymphoma, and multicentric Castleman's disease. Phosphatidylinositol 3-kinase (PI3K), RhoAGTPase, and Diaphanous-2 (a RhoA-GTPase-activated adaptor molecule involved in microtubule activation) act as signal molecules in the entry process of the virus [77]. Reduction of HHV-8 infection and decrease in the cellular signals associated with viral infection in raft-disrupted cells suggest that membrane rafts in microvascular dermal endothelial cells are essential for HHV-8 infection and gene expression.

Vaccinia virus is established as a vaccine that eradicated smallpox disease. After virus infection, viral envelope proteins, A14, A17L and $\mathrm{D} 8 \mathrm{~L}$, except $\mathrm{H} 3 \mathrm{~L}$ are present in membrane rafts. Initial attachment of the virions with viral receptor glycosaminoglycans is not required for membrane raft formation. On the other hand, cholesterol-containing membrane rafts are essential for vaccinia virus penetration into a wide variety of mammalian cells from different hosts [78].

Human coronavirus, which is responsible for $10-30 \%$ of all common colds manifesting upper respiratory and gastrointestinal symptoms, internalizes into cells through caveola-dependent endocytosis after attachment to the viral receptor CD13 present in rafts. Virus infection is inhibited by caveola destruction with cholesterol depletion and RNAi for caveolin-1 [79]. Mouse hepatitis virus (MHV), which is one of the murine coronaviruses, binds to nonraft membranes and then shifts to raft membranes for virus entry and the fusion process. Membrane rafts are not incorporated into MHV virions and not associated with spike protein of MHV on the Golgi membrane, which is the site of virus assembly and budding. Membrane rafts are not probably required for the virus release process $[80,81]$. SARS-CoV is the most extensively studied human coronavirus that causes severe acute respiratory syndrome (SARS). SARS-CoV associates with membrane rafts as an entry port after binding to the virus receptor angiotensin-converting enzyme 2 (ACE2) present in rafts of Vero E6 cells [82, 84]. Studies on the expression of dominant-negative Eps15, which is required for the clathrin-dependent pathway, and caveolin-1, indicate that SARS-CoV and feline infectious peritonitis virus (FIPV), which causes a lethal chronic disease in cats, internalize into cells via a clathrin- and caveola-independent pathway. On the other hand, inhibition of virus infection by cholesterol depletion has demonstrated entry of these viruses into cells by raft-dependent endocytosis [83, 85]. These findings indicate that raft-dependent endocytosis except 
clathrin- and caveola-dependent pathway is important for the virus infection.

Flaviviruses enter target cells through receptor-mediated endocytosis and are delivered into acidic endosomes for uncoating of the virion and release of viral RNA into the cytoplasm. Severe forms of WNV disease manifest as neurological symptoms such as meningitis, encephalitis, and poliomyelitis. A nonpathogenic laboratory strain of WNV (Sarafend strain) binds to $\alpha_{V} \beta_{3}$ integrin as a virus receptor and enters cells by clathrin-coated endocytosis and by activation of focal adhesion kinase (FAK) $[129,130]$. On the other hand, NY385-99 strain of WNV utilizes raft-mediated endocytosis independent of $\alpha_{\mathrm{V}} \beta_{3}$ integrin and FAK activation [86].

DEN, which is the most important arthropod-borne human pathogen, represents clinical manifestations from a simple self-limited febrile illness known as dengue fever to a hemorrhagic fever and potentially fatal hemorrhagic shock syndrome. Receptor candidates of DEN have been reported to be dendritic cell-specific ICAM 3-grabbing non-integrin (DC-SIGN) [131], heparan sulfate [132], heat shock proteins (HSPs) [88], and neolactotetraosylceramide [133]. HSP90 and HSP70 are part of a receptor complex of DEN, which are associated with membrane rafts required for virus entry in neuroblastoma and human monocytes/macrophages [88, 89]. Although DC-SIGN is present in membrane rafts [134] and neolactotetraosylceramide is a type of sphingolipid known as the main components of rafts, there is no direct evidence between rafts and DEN entry associated with these receptors. Membrane rafts are also required for the JEV entry process [89], possibly related to putative virus receptors, HSP70 [135] and heparan sulfate [136] like those of DEN.

$\mathrm{HCV}$ infection is a major cause of chronic liver diseases, including chronic hepatitis, hepatic steatosis, cirrhosis, and hepatocellular carcinoma. Cholesterol depletion has an inhibitory effect on $\mathrm{HCV}$ entry through binding to CD81 that is present in cholesterol-enriched microdomains [90]. Sphingomyelin hydrolysis has a strong inhibitory effect on $\mathrm{HCV}$ entry since ceramide enrichment of the plasma membrane leads to a decrease in the level of CD81 present at the cell surface by inducing CD81 internalization [91]. Thus, CD81-mediated HCV entry is partially dependent on major raft components, including cholesterol and sphingomyelin.

Alphaviruses such as Semliki Forest virus and Sindbis virus, which are arthropod borne-pathogens of infectious arthritis and rashes, require cholesterol for low-pH triggered fusion within acidic endosomes of virus entry processes [92, 93, 96]. E1 fusion protein of Semiliki Forest virus directly binds to cholesterol, promoting virus fusion and infection in cholesterol-dependent manner [137]. However, alphaviruses may not require membrane rafts for cholesterol-dependent promotion of fusion with the target membrane [95]. Similarly, entry of LCMV is also known to be raftindependent but requires membrane cholesterol [97]. Cholesterol dependence may not necessarily be linked to the function of membrane rafts in LCMV entry.

$\mathrm{PrP}$ is an infectious protein lacking a genome. $\mathrm{PrP}^{\mathrm{Sc}}$, which is a protease-resistant isoform of the host protein $\mathrm{PrP}^{\mathrm{C}}$, is the infectious component that causes fetal neurode- generative transmissible spongiform encephalopathies such as Creutzfeldt-Jakob disease in humans. Association of $\operatorname{PrP}^{\mathrm{C}}$ with cholesterol-enriched membrane rafts facilitates its correct folding. Depletion of cholesterol but not sphingolipids leads to its missfolding to $\operatorname{PrP}^{\mathrm{Sc}}$ [98-100]. Membrane rafts are believed to be the conversion site of $\operatorname{PrP}^{\mathrm{C}}$ to $\operatorname{PrP}^{\mathrm{Sc}}$. Moreover, increased level of the glycosphingolipid GM1 (an essential raft marker) on fibroblast cells by a mouse parvovirus (Parvoviridae) infection may promote prion infection through the incorporation of exogenous $\mathrm{PrP}^{\mathrm{Sc}}$ into rafts [101].

\section{ROLE OF MEMBRANE RAFTS IN VIRUS GENOME REPLICATION, ASSEMBLY, AND BUDDING}

The involvement of virus assembly and budding with membrane rafts has been studied by investigating inhibitory effect of virion formation and production on disruption of membrane rafts by cholesterol depletion. In the condition of cholesterol depletion, virion formation and production in virus-infected cells are rescued by addition of exogenous cholesterol. Biochemical methods for evaluating viral assembly and budding have been performed by measuring whether viral structural proteins during virus formation and assembly are detected within detergent-insoluble fraction or are colocalized with raft-markers such as caveolin-1, flotillin, and GM1. Raft-dependent virus budding and replication have also been investigated by inhibition of caveola formation using RNAi and dominant-negative protein expression for normal caveolin-1 knockdown. If the association sites on viral structural proteins are identified, it will be possible to generate mutated viral proteins that do not associate with membrane rafts. Virus assembly and budding can also be evaluated by measuring intracellular transport or incorporation rate of these mutated proteins into virions or replicatability of reverse genetics viruses possessing these proteins. When budding of enveloped viruses takes place in membrane rafts, localization of the virions within raft can be observed by an electronic microscope.

The role of membrane rafts in the intracellular assembly of nonenveloped viruses has been reported only for rotavirus [29, 138-141] and bluetongue virus [142], belonging to the family Reoviridae. Rotavirus replication occurs in large inclusions (known as viroplasm) in the cell cytoplasm, where viral RNA is replicated and double-layered particles are assembled. These particles translocate across the ER membrane by interactions of the viral capsid protein VP6 with the nonstructural transmembrane glycoprotein NSP4, which has been characterized as an ER intracellular receptor critical to viral morphogenesis and a viral enterotoxin for intestinal cells. During viral translocation through the ER, the virus acquires a transient lipid envelope that is finally lost and replaced by viral surface spike proteins, VP4 and VP7. In this process, the involvement of transient enveloped particles with rafts is highly questionable since rafts are thought to be absent from the ER. Association of VP4 with rafts in the extrareticular compartment promotes rotavirus morphogenesis as a final assembly platform and apical targeting toward the release process [29, 138, 139], which are significantly dependent on the raft heterogeneity (the nature and proportion of phospholipids and glycosphingolipids) [140]. Moreover, NSP4 undergoes Golgi networkspecific processing for its $N$-glycans through caveola- 
dependent Golgi network-bypassing transport [141]. Bluetongue virus infection causes a non-contagious, arthropod-borne viral disease in both domestic and wild ruminants. Association of SNARE (soluble $\mathrm{N}$ ethylmaleimide-sensitive fusion attachment protein receptor) domain in the viral outer capsid VP5 with membrane rafts may play an important role in its membrane targeting and virus assembly [142].

Involvement of membrane rafts in viral RNA synthesis of enveloped viruses has been reported for HCV [143-146], respiratory syncytial virus (RSV; Paramyxoviridae) [147, 148], DEN [149], and JEV [149]. Association of HCV nonstructural (NS) proteins with cholesterol-enriched membrane rafts in the Golgi-derived membrane forms the replication site of HCV RNA synthesis and protects it from RNase and protease [143, 144]. A lipophilic long-chain base compound, NA255, has been identified as a small-molecule $\mathrm{HCV}$ replication inhibitor from a secondary fungal metabolite. NA255 disrupts the association among HCV NS proteins on membrane rafts by prevention of de novo synthesis of sphingolipids, major membrane raft components [145]. Since cholesterol-depleted or sphingomyelinhydrolyzed virions lose ability of cellular internalization but not cell attachment, incorporation of cholesterol and sphingolipid into HCV particles is also important for virion maturation and infectivity. Although HCV structural proteins significantly localizes into rafts on the cellular membrane, it is unclear whether lipids on the virion form rafts or not. Membrane rafts may function as a budding site of $\mathrm{HCV}$ in the ER [146].

Human RSV infection is a major cause of severe lower respiratory tract disease in infants, children, immunosuppressed individuals, and the elderly. The viral proteins, nucleoprotein $(\mathrm{N})$, phosphoprotein $(\mathrm{P})$, large polymerase subunit (L), matrix protein (M) and M2-1, are present within membrane rafts in virus-infected cells. A viral RNP core is formed by interaction of the viral genomic RNA with $\mathrm{N}, \mathrm{P}, \mathrm{L}$ and M2-1 proteins. The M protein is located between viral envelope and the RNP. The association of RSV RNP with membrane rafts leads to efficient RNA polymerase activity that may be required for interaction with the cellular factor HSP70, which is one of the virus receptor candidates, via membrane rafts in an ATP-dependent manner $[147,148]$.

Membrane rafts are associated with a non-structural glycoprotein (NS1) of all four DEN serotypes and JEV, which is detected in the RNA replication complex. Efficient RNA replication of flaviviruses may require NS1 transport to the plasma membrane after contact of GPI-linkage of NS1 with membrane rafts in the Golgi apparatus [149].

The role of membrane rafts in the assembly and budding of enveloped viruses has been investigated for influenza virus [59, 63, 150-160], HIV-1 [63, 161-173], HTLV-1 [174], measles virus (Paramyxoviridae) [63, 175, 176], Sendai virus [Paramyxoviridae] [177, 178], Newcastle disease virus (NDV; Paramyxoviridae) [179, 180], RSV [147, 148, 181-184], HSV [185, 186], murine cytomegalovirus (MCMV; Herpesviridae) [187], Ebola virus $[70,188]$, Marburg virus [70], and vesicular stomatitis virus (VSV; Rhabdoviridae) [189, 190].
Influenza virus particles consist of the viral RNP with an envelope that includes two spike glycoproteins, HA and neuraminidase (NA), and ion channel M2 protein on the outer surface and internal M1 protein and nonstructural NS2 protein on the inner surface. Membrane rafts are associated with the transmembrane domains and cytoplasmic tails of HA and NA, with the short transmembrane domains of M2, and with NP but not with M1. These domains of HA and M2 possess palmitoylated cysteine residues that can associate with lipids and cholesterol in rafts. Although these domains of NA are essential for the association with rafts, there is no evidence that NA possesses palmitoylated residues. The mechanism by which NP associates with rafts remains unknown [104, 154-156, 191]. HA, NA, NP and M2 independently utilize membrane rafts together with apical targeting signal sequence for the apical sorting process, leading to efficient preferential budding and release of progeny viruses from the apical surface membrane. However, direct interactions with membrane rafts are not necessarily essential for apical sorting of these viral proteins, indicating that they can also interact with apical sorting machineries outside their membrane rafts $[150,152-154$, 156]. For example, cellular protein VIP17/MAL, a raftassociated protein, is involved in apical transport of HA in dog kidney MDCK cells [192]. M1, which is not dependently associated with rafts, is incorporated into membrane rafts by interactions with cytoplasmic tails of both HA and M2, which promote the recruitment of internal viral proteins and viral RNP to the plasma membrane for efficient virus assembly and budding [154, 193]. Although M1 has been reported to play a critical role in viral assembly and budding $[194,195]$, a recent study has indicated that HA and NA, but not M1, are required for assembly and budding of influenza virus particles [159].

Replication of influenza viruses in the GM-95 mutant cell line of mouse B16 melanoma, which cannot synthesize major glycosphingolipids such as gangliosides due to lack of the ceramide glycosyltransferase gene, did not show a significant reduction in comparison with that in the parent cells [196]. It seems that gangliosides, major components of rafts, are not essential for the influenza virus life cycle. This suggestion for virus assembly and budding is supported by evidence that mutant viruses possessing alteration of raftbinding domains in HA and NA have the ability to produce infectious progeny virus $[59,155]$ and evidence that membrane raft disruption enhances virus budding from MDCK cells [160]. How do membrane rafts help the influenza virus life cycle? Concentration and clustering of HA and NA in same membrane rafts promote efficient incorporation of these viral surface proteins into progeny viral membrane in the budding process [59, 155] since progeny virus particles were selectively budded together with membrane rafts on the cell surface [151]. At that time, M2 is distributed in a different type of membrane rafts from those in which HA and NA are distributed. M2 is also located in non-raft compartments on the cell surface. Therefore, M2 results in poor incorporation into the progeny viral membrane [157]. Moreover, membrane raft disruption causes a decrease in progeny virus infectivity concomitantly with an enhancement of virus particle release from infected cells [160]. Taken together, the results suggest that the role of membrane rafts in the influenza virus life cycle 
contributes to efficient incorporation of raft-associated viral proteins into the progeny viral membrane, which enhances progeny virus infectivity, rather than specific sorting and assembly of viral structural components and pinching-off of viral membrane from the plasma membrane.

The tight association of newly synthesized HA transferred to infected cell surface with membrane rafts triggers the activation of the cellular Raf/MEK/ERK signaling of MAPK via PKC $\alpha$ activation. MAPK activation induces viral RNP export from the nucleus to the cytoplasm, leading to an enhancement of infectious progeny virus production [158]. Our recent study showed that sulfatide, a sulfated glycosphingolipid, was required for efficient virus replication and that association of newly synthesized HA transferred to the infected cell surface with sulfatide induced viral RNP export from the nucleus to the cytoplasm, leading to enhancement of infectious progeny virus formation [197]. Thus, association of HA with sulfatide may trigger MAPK activation to enhance viral RNP export. Some studies have shown the existence of sulfatide within membrane rafts [198, 199], but lipid composition of purified influenza virus grown in embryonated eggs does not contain any acidic glycosphingolipids including sulfatide [154]. The raft localization of sulfatide leading to enhancement of viral RNP export has not yet been ascertained.

HIV-1 utilizes membrane rafts as a platform for viral assembly and budding [161, 167]. Modification of the Nterminus of HIV-1 Gag protein with myristic acid is essential for HIV-1 assembly and budding [200]. Myristiric acids of Gag protein interact with membrane rafts in the plasma membrane. Gag protein is incorporated into HIV-1 particle as an internal structural protein [167]. During the budding process, Gag multimerization is induced by Gag-Gag interactions via the $\mathrm{N}$-terminus of the viral nucleocapsid (NC domain). Interaction of $\mathrm{Gag}$ proteins with the plasma membrane and membrane rafts may be enhanced or stabilized by lower-ordered Gag multimerization, but not required for higher-order Gag multimerization. The role of membrane rafts in enhancement of Gag-Gag interaction is not clear [165]. The viral surface glycoprotein complex (gp120 and gp41) is incorporated into the HIV-1 envelope together with membrane rafts by interactions of Gag protein with the cytoplasmic tail of gp41, which stabilizes the gp120-gp41 interaction. The palmitoylated cytoplasmic tails of gp41 are required for association with rafts, whereas interactions between gp41 and Gag protein are not involved in the association with rafts. Moreover, membrane raft association with gp41 or Gag protein is not essential for HIV-1 assembly, infectious progeny virus production, and surface trafficking [164, 168, 169]. However, quantal association of Gag protein with cholesterol-enriched rafts facilitates HIV-1 particle production by enhancement of both Gag-membrane interaction and Gag multimerization [172, 173]. The Nef protein encoded by primate lentiviruses augments virus replication and increases the pathogenic potential of HIV. The myristoylated N-terminus and its neighboring basic arginine and lysine residues of Nef increase viral transcription and HIV-1 virion infectivity by association with GM1- and cholesterol-enriched membrane rafts. Nef also binds to both the plasma membrane and viral structural proteins and participates directly in formation of the budding scaffold, leading to incorporation of Nef into virions, concomitantly with viral structural proteins $[162$, $163,166]$. The N-terminus of Nef determines the differential membrane avidities and selective incorporation into a specific membrane raft for surface membranes or for subcellular membranes [170]. Moreover, Nef modulates the lipid composition of virions and host cell membrane rafts through activation of lipid kinases such as PI3K [171].

HTLV-1 assembly is also inhibited by a decrease of Gag association with membrane rafts by interferon $\alpha-2$ a treatment [174].

Measles virus infection is responsible for an acute respiratory disease and causes the death of over one-million children every year principally because of virus-induced immunosuppression of lymphocyte function. Membrane rafts act as a platform of measles virus assembly but not the budding process. The transmembrane domain of the viral surface fusion (F) protein has two palmitoylated cysteines, which possibly associate with membrane rafts [201]. The F protein is synthesized as an inactive precursor $\left(\mathrm{F}_{0}\right)$ that is proteolytically cleaved in the trans-Golgi network to form a biologically active protein consisting of the disulfide-linked subunits $\mathrm{F}_{1}$ and $\mathrm{F}_{2}$. The mature form of the two viral glycoproteins, both hemagglutinin $(\mathrm{H})$ and $\mathrm{F}$ protein but not the $\mathrm{F}_{0}$ precursor, is preferentially incorporated into membrane rafts after transport to the trans-Golgi network. The internal structural proteins, $\mathrm{M}$ and $\mathrm{N}$, associate with membrane rafts via saturated acyl chains, independently of the presence of the viral surface $H$ and $F$ proteins. The nonstructural $\mathrm{V}$ protein is excluded from membrane rafts. The $\mathrm{M}$ protein can interact with the cytoplasmic tail of the $\mathrm{F}$ protein in $\mathrm{H}-\mathrm{F}$ complexes and with the $\mathrm{N}$ protein, which in turn can bind to the viral internal structural proteins, $\mathrm{P}$ and $\mathrm{L}$. Eventually, M-RNP complexes, containing N, P and L with viral RNA, interact with the surface membrane and H-F complexes via the $\mathrm{M}$ protein and the $\mathrm{F}$ protein in membrane rafts. This interaction results in efficient assembly of measles virus prior to the budding process $[175,176]$.

Sendai virus, which is also known as murine parainfluenza virus type 1 , is responsible for a highly transmissible respiratory tract infection in mice, hamsters, guinea pigs, rats, and occasionally pigs. The two viral surface proteins, hemagglutinin-neuraminidase $(\mathrm{HN})$ protein and $\mathrm{F}$ protein, associate with membrane rafts. When the viral internal $\mathrm{M}$ protein alone is expressed, it is not located in membrane rafts. Mature HN-F complex specifically interacts with $\mathrm{M}$ protein via both the cytoplasmic tail and the transmembrane domain of $\mathrm{F}$ protein. Thus, $\mathrm{M}$ protein is present in membrane rafts, where has been suggested to assemble viral structural proteins to virions [177]. However, further study led to the conclusion that the assembly complex found in membrane rafts does not constitute a direct precursor of Sendai virus particle budding [178]. There is another possible route in Sendai virus assembly.

NDV is a highly contagious pathogen of zoonotic bird disease affecting many domestic and wild avian species. The ordered assembly and budding of infectious progeny NDV particles preferentially occur in membrane rafts associated with the cortical cytoskeleton [179]. Furthermore, intact membrane raft domains in NDV-infected cells, but not in virion envelopes, facilitate the proper formation or maintenance of the viral surface HN-F glycoprotein 
complexes and the virion incorporation of glycoprotein complexes capable of initiating virus-cell membrane fusion [180].

The viral surface attachment $(\mathrm{G})$ protein and the internal $\mathrm{M}$ and $\mathrm{N}$ protein of RSV are present in membrane rafts. RSV contains a raft marker, caveolin, in the viral envelope and induces the cellular distribution of phosphocaveolin-1 in infected cells. Therefore, RSV assembly at the plasma membrane has been shown to occur within specialized membrane rafts that contain a high caveolin content [181, 182]. The cytoplasmic tail, but not the transmembrane domain and the ectodomain of $\mathrm{F}$ protein, plays a critical role in its cellular localization and production of infectious progeny virus, dependently on interaction of $\mathrm{F}$ protein with membrane rafts [183]. Moreover, like a function of HIV-1 Nef [171], RSV infection induces production of phosphatidylinositol 4,5-bisphosphate (PIP2) and phosphatidylinositol 3,4,5-triphosphate (PIP3) in the lipid composition of membrane rafts within virus inclusion bodies through lipid kinases containing PI3K. This change plays a role in the assembly and budding of progeny virus [184].

The HSV tegument contains the less-abundant virion host shutoff (vhs) protein encoded by the HSV late gene UL41, which stimulates the turnover of all kinetics of viral mRNA and is likely to be important in removing immediate-early and early viral transcripts to facilitate the switch to late gene expression. Only a small proportion of total cellular vhs is associated with membrane rafts. Nevertheless, it represents a large proportion of the vhs present in HSV-containing cytoplasmic organelles, suggesting that membrane rafts may correlate with assembly of vhs into the tegument [185]. The UL11 and UL51 gene products of HSV are membraneassociated tegument proteins that are incorporated into the HSV envelope during virion maturation. HSV UL11 is associated with cholesterol- and glycosphingolipid-enriched membrane rafts via its posttranslational myristoylation and palmitoylation in the Golgi apparatus, but UL51, which is only palmitoylated, has no such association. It seems that UL11 and UL51 play roles at different steps in virion maturation [186]. Involvement of membrane rafts in HSV assembly and budding remains unclear. MCMV (belonging to the beta-herpes virus UL78 family) M78 protein, a 7 transmembrane receptor homologue, is transported to the surface membrane of infected cells but is rapidly and constitutively endocytosed through both clathrin-dependent and caveola/raft-dependent internalization pathways. Modification of M78 subcellular localization during the course of infection may contribute to the incorporation of M78 into the virion envelope during virus maturation [187].

Ebola virus and Marburg virus utilize membrane rafts incorporating the viral glycoprotein (GP) as a platform for budding from host cells. Hence, released virions incorporate the raft-associated molecule GM1 but not transferrin receptor, which is a protein excluded from membrane rafts [71]. The matrix protein VP40 of Ebola virus, which plays a critical role in virus assembly and budding, oligomerizes within membrane rafts. The cellular TSG101 protein, a component of the vacuolar protein sorting machinery, actively redirects to membrane rafts at the cell surface, along with VP40, due to VP40 binding with TSG101 through a PTAP motif. Thus, budding complexes containing VP40,
TSG101, and possibly other components accumulate in membrane rafts to serve in virus budding [188].

The VSV budding occurs in membrane microdomains containing viral surface $G$ glycoproteins with a range of sizes, some of which are $100-150 \mathrm{~nm}$ in size and smaller than the virus envelope (approximately 100-150 nm) and others of which extend in size to a maximum of $300-400 \mathrm{~nm}$ from the tip of the virus budding site $[189,190]$. However, immunoelectron microscopy observation has not provided evidence that gold-labeled $\mathrm{G}$ protein-containing microdomains are equivalent to lipid-enriched membrane rafts. Besides, microdomains of $300-400 \mathrm{~nm}$ in size are much larger than the definition of raft size of 10-200 nm [3]. A recent study has also shown that most wild-type G protein is not incorporated into membrane rafts in VSV-infected osteoclasts [202]. Resolution of these contradictions on membrane rafts will be expected in the future study of VSV budding.

\section{INVOLVEMENT OF MEMBRANE RAFTS IN VIRUS DISEASES}

Membrane rafts act as a scaffold of many cellular signal transductions. Involvement of membrane rafts in many virus diseases is often responsible for up- or down-regulation of cellular signal transductions. Rhinovirus serotype 39 colocalizes with Src kinases, PI3K, and the serine threonine kinase Akt in membrane rafts with a few minutes after infection. Src and PI3K are upstream activators of Akt and the interleukin-8 (IL-8) promoter. Rhinovirus infection activates these kinases and IL-8 expression, resulting in exacerbation of asthma and chronic obstructive pulmonary disease [203]. HTLV-1 Tax1 protein actively recruits IкB kinases (IKK) to membrane rafts for persistent activation of $\mathrm{NF}-\kappa \mathrm{B}$, which promotes $\mathrm{T}$ cell proliferation, thereby contributing to HTLV-1-induced $\mathrm{T}$ cell leukemia. Flaviviruses such as DEN type 2 and JEV activate the PI3K/Akt pathway that induces anti-apoptosis to protect infected cells from early apoptotic cell death. However, PI3K/Akt signaling is not essential for flavivirus replication. A balance between apoptotic signaling and antiapoptotic signaling, which are triggered by interplay between the host and virus, regulates the outcome of flavivirus infection [204]. The partitioning of measles virus $\mathrm{F}$ protein into highbuoyant-density membrane rafts activates the alternative pathway of human complement, independently of both CD46 and CD55, which regulate the complement activation and do not exist in the same rafts as F protein. Thus, measles virus infection induces an inflammatory response through alternative complement activation [205]. Measles virusinduced immnosuppression is also responsible for signal transduction alteration such as $\mathrm{PI} 3 \mathrm{~K}$ in $\mathrm{T}$ cell membrane rafts [206]. Tyrosine kinase-interacting protein (Tip) of lymphotropic herpesvirus saimiri (HVS) is targeted to membrane rafts in $\mathrm{T}$ cells and downregulates $\mathrm{T}$ cell receptor (TCR) and CD4 surface expression. Tip is required for the cellular membrane deformation of $\mathrm{T}$ cells, but not for viral replication, inducing lymphoma in primates [207]. Persistent HPV infection results in epithelial cell transformation that is responsible for cellular polarity disturbance, which is implicated in MAL and BENE, components of the membrane raft's machinery for apical sorting of membrane proteins. Down-regulation of MAL and BENE genes from 
HPV infection may play an important role in human cervical squamous cell cancer development [22]. The "early" gene oncoproteins E6 and E7 of high-risk HPV are known to be invariably expressed in cervical cancers by alteration of several signals containing inactivating p53, blocking apoptosis, activating telomerase, and disrupting cell adhesion [208]. The additional oncoprotein E5 of high-risk HPV 16 increases the expression and association of both GM1 and caveolin-1, which are components of membrane rafts, on the cell surface. This up-regulation of membrane rafts helps HPV immune evasion by inhibiting cytotoxic $\mathrm{T}$ lymphocytes [209].

Viral replication efficiency, viral infection site, and viral disease are frequently controlled by membrane rafts in host cells and immune cells. GM1 expression and asialo-GM1 expression in membrane rafts of lung lymphocytes are differentially regulated by $\mathrm{T}$ cells and natural killer (NK) cells in RSV infection. Asialo-GM1 expression in NK cells may promote RSV clearance by increasing lung IFN- $\gamma$ levels in mice [210]. The pseudorabies virus Us9 protein associates with membrane rafts and then targets viral structural proteins to neuronal axons. Consequently, the virus spreads from presynaptic to post-synaptic neurons and cells of the mammalian nervous systems [18]. HSV-1 infection interacts with Alzheimer's disease susceptibility by virus binding to HSPGs, or $\alpha$-2-macroglobulin, nectin receptors, blood-borne lipoproteins, and apolipoprotein E (APOE). Reduction of cholesterol on the plasma membrane by cholesterol-lowering statins has been linked with reduced risk of developing Alzheimer's dementia. Since HSV-1 uptake into cells is cholesterol- and membrane raft-dependent, cholesterol reduction may decrease the availability of membrane raftmediated pathways to spread HSV-1 within the brain [211, 212]. Membrane raft-dependent phagocytosis of HCVinfected apoptotic vesicles containing viral double-strand RNA (dsRNA) is required for maturation of human monocyte-derived dendritic cells (MoDCs). HCV JFH1 strain, which can efficiently replicate in cell culture, does not directly stimulate MoDCs to activate T cells and NK cells, but raft-dependent phagocytosis of infected apoptotic cells and their interaction of viral dsRNA with the Toll-like receptor 3 (TLR3) pathway in MoDCs contribute to maturation of MoDCs and activation of $\mathrm{T}$ and NK cells [213].

\section{CONCLUSION AND PERSPECTIVES}

Many recent studies have suggested that membrane rafts are involved in the process of the viral life cycle, including cell entry, genome replication, assembly, budding, and virusassociated diseases (Tables 1-4). What is the role of membrane rafts in virus replications? Recent studies have demonstrated that membrane rafts are not necessary in many virus replications. For virus entry into cells, various viruses, including many nonenveloped viruses, use several entry pathways, not only caveola/raft-dependent, but also clathrin-dependent or another endocytosis. For the assembly and budding representative of many enveloped viruses, membrane raft disruption on host cells facilitates formation and production of progeny virions, but these virions have a little infectivity and low viral components. For apical sorting of viral proteins, membrane rafts appear not to be essential for cellular membrane targeting of viral structural proteins. Nevertheless, why do many viruses employ raft-associated infection cycles? Membrane rafts for the virus assembly and budding generally contribute to produce high-infective progeny virions, because of concentration and efficient incorporation of viral structural components from the assembly and budding sites to the virion. For similar reasons, concentration of viral polymerases in membrane rafts acts as a platform for more efficient replication of viral genomes. Furthermore, usage of several endocytosis pathways provides an advantage for virus entry into a wider range of hosts, cell lines, and tissues. Concentration of viral fusion protein in a raft-associated receptor or caveola/raftdependent endocytosis may enhance the virus-cell fusion process, leading to increased infection. Taken together, the results indicate that viruses do not necessarily require and probably utilize membrane rafts for more efficiency in virus entry, viral genome replication, high-infective virion production, and cellular signaling activation toward advantageous virus replication.

Almost studies of membrane rafts in virus life cycle have been performed by classical approaches such as treatment of cholesterol-disrupting reagents, detergent-insoluble fractionation, and microscopic observation of colocalization with

Table 1. Raft-Associated Processes of Non-Enveloped DNA Viruses

\begin{tabular}{|c|c|c|c|}
\hline Family & Genome & Virus & Process \\
\hline \hline Adenoviridae & 1 segment & Species C human adenovirus (HAdV) & Entry \\
& Linear dsDNA & Entry & Entry \\
\hline Papovaviridae & 1 segment & Simian virus 40 (SV40) & Entry \\
& Circular dsDNA & BK virus & Entry \\
& & JC virus & Immune evasion \\
& & Bovine papillomavirus & Cancer development \\
\hline Parvoviridae & 1 Human papillomavirus (HPV) & & Prion infection? \\
\hline
\end{tabular}


Table 2. Raft-Associated Processes of Non-Enveloped RNA Viruses

\begin{tabular}{|c|c|c|c|}
\hline Family & Genome & Virus & Process \\
\hline Picornaviridae & $\begin{array}{c}1 \text { segment } \\
\text { Linear ssRNA }\end{array}$ & $\begin{array}{l}\text { Echovirus type } 1 \text { and } 11 \\
\text { Enterovirus } \\
\text { Rhinovirus } \\
\text { Coxsackie virus A9 and B4 }\end{array}$ & $\begin{array}{c}\text { Entry } \\
\text { Entry } \\
\text { Entry } \\
\text { Cellular kinase activation } \\
\text { Entry }\end{array}$ \\
\hline Reoviridae & $\begin{array}{l}\text { 10-12 segments } \\
\text { Linear dsRNA }\end{array}$ & $\begin{array}{c}\text { Rotavirus } \\
\text { Bluetongue virus }\end{array}$ & $\begin{array}{c}\text { Entry } \\
\text { Assembly } \\
\text { Apical targeting } \\
\text { Golgi transport } \\
\text { Entry } \\
\text { Assembly } \\
\text { Membrane targeting }\end{array}$ \\
\hline
\end{tabular}

Table 3. Raft-Associated Processes of Enveloped DNA Viruses

\begin{tabular}{|c|c|c|c|}
\hline Family & Genome & Virus & Process \\
\hline Herpesviridae & $\begin{array}{c}1 \text { segment } \\
\text { Linear dsDNA }\end{array}$ & $\begin{array}{l}\text { Epstein-Barr virus (EBV) } \\
\text { Herpes simplex virus-1 (HSV-1) } \\
\text { Porcine herpesvirus-1 } \\
\text { (Pseudorabies virus) } \\
\text { Human herpesvirus-6 (HHV-6) } \\
\text { Human herpesvirus-8 (HHV-8) } \\
\text { Murine cytomegalovirus (MCMV) } \\
\text { Lymphotropic herpesvirus saimiri } \\
\text { (HVS ) }\end{array}$ & $\begin{array}{c}\text { Entry } \\
\text { Entry } \\
\text { Assembly? } \\
\text { Progeny virion infectivity } \\
\text { Alzheimer's disease } \\
\text { Entry } \\
\text { Virus spread in neurons } \\
\text { Entry } \\
\text { Entry } \\
\text { Assembly? } \\
\text { Lymphoma }\end{array}$ \\
\hline Poxviridae & $\begin{array}{c}1 \text { segment } \\
\text { Linear dsDNA }\end{array}$ & Vaccinia virus & $\begin{array}{c}\text { Entry } \\
\text { Penetration }\end{array}$ \\
\hline
\end{tabular}

raft markers. Recent studies have been increasingly approached by molecular methods such as RNAi and dominant negative against Eps15 and caveolin-1. However, further study will require several new approaches to elucidate the functions of various types of membrane rafts. An understanding of the function of membrane rafts in the virus life cycle may contribute to the elucidation of the essential cellular functions of membrane rafts and to the development of new antivirus chemotherapy against directly viruses and virus-associated diseases. 
Table 4. Raft-Associated Processes of Enveloped RNA Viruses

\begin{tabular}{|c|c|c|c|}
\hline Family & Genome & Virus & Process \\
\hline Arenaviridae & $\begin{array}{c}2 \text { segments } \\
\text { Circular ssRNA }\end{array}$ & $\begin{array}{l}\text { Lymphocytic choriomeningitis virus } \\
\text { (LCMV) }\end{array}$ & Entry \\
\hline Coronaviridae & $\begin{array}{c}1 \text { segment } \\
\text { Linear ssRNA }\end{array}$ & SARS-CoV, coronavirus & Entry \\
\hline Filoviridae & $\begin{array}{c}1 \text { segment } \\
\text { Linear ssRNA }\end{array}$ & $\begin{array}{l}\text { Ebola virus } \\
\text { Marburg virus }\end{array}$ & $\begin{array}{l}\text { Entry } \\
\text { Assembly } \\
\text { Budding } \\
\text { Entry } \\
\text { Budding }\end{array}$ \\
\hline Flaviviridae & $\begin{array}{c}1 \text { segment } \\
\text { Linear ssRNA }\end{array}$ & $\begin{array}{c}\text { Dengue virus (DEN) } \\
\text { Japanese encephalitis virus (JEV) } \\
\text { West Nile virus (WNV) } \\
\text { Human hepatitis C virus( HCV) }\end{array}$ & $\begin{array}{c}\text { Entry } \\
\text { Vrial RNA replication } \\
\text { Anti-apoptosis } \\
\text { Entry } \\
\text { Vrial RNA replication } \\
\text { Anti-apoptosis } \\
\text { Entry } \\
\text { Entry } \\
\text { Vrial RNA replication } \\
\text { Progeny virion infectivity } \\
\text { Budding? } \\
\text { MoDC maturation }\end{array}$ \\
\hline Orthomyxoviridae & $\begin{array}{l}\text { 6-8 segments } \\
\text { Linear ssRNA }\end{array}$ & Influenza A virus & $\begin{array}{c}\text { Fusion } \\
\text { Assembly } \\
\text { Budding } \\
\text { Progeny virion infectivity } \\
\text { Apical targeting? } \\
\text { Viral proton channel? }\end{array}$ \\
\hline Paramyxoviridae & $\begin{array}{c}1 \text { segment } \\
\text { Linear ssRNA }\end{array}$ & $\begin{array}{c}\text { Measles virus } \\
\text { Newcastle disease virus (NDV) } \\
\text { Respiratory syncytial virus (RSV) } \\
\text { Sendai virus }\end{array}$ & $\begin{array}{c}\text { Assembly } \\
\text { Inflammatory response } \\
\text { Immnosuppression } \\
\text { Assembly } \\
\text { Budding } \\
\text { Progeny virion infectivity } \\
\text { Viral RNA replication } \\
\text { Assembly } \\
\text { Budding } \\
\text { IFN- } \gamma \text { expression } \\
\text { Assembly? }\end{array}$ \\
\hline Retroviridae & $\begin{array}{c}1 \text { segment } \\
\text { Linear ssRNA }\end{array}$ & $\begin{array}{l}\text { Human immunodeficiency virus } \\
\text { (HIV) }\end{array}$ & $\begin{array}{c}\text { Entry } \\
\text { Assembly } \\
\text { Budding } \\
\text { Entry } \\
\text { Fusion } \\
\text { Assembly } \\
\text { T cell leukemia }\end{array}$ \\
\hline Rhabdoviridae & $\begin{array}{c}1 \text { segment } \\
\text { Linear ssRNA }\end{array}$ & Vesicular stomatitis virus (VSV) & Budding? \\
\hline Togaviridae & $\begin{array}{l}\text { 6-8 segments } \\
\text { Linear ssRNA }\end{array}$ & $\begin{array}{l}\text { Semliki forest virus } \\
\text { Sindbis virus }\end{array}$ & $\begin{array}{l}\text { Fusion? } \\
\text { Entry? }\end{array}$ \\
\hline
\end{tabular}




\section{REFERENCES}

[1] Pelkmans L, Helenius A. Endocytosis via caveolae. Traffic 2002; 3: $311-20$

[2] Pelkmans L. Secrets of caveolae- and lipid raft-mediated endocytosis revealed by mammalian viruses. Biochim Biophys Acta 2005; 1746: 295-304.

[3] Pike LJ. Rafts defined: a report on the Keystone symposium on lipid rafts and cell function. J Lipid Res 2006; 47: 1597-8.

[4] Stang E, Kartenbeck J, Parton RG. Major histocompatibility complex class I molecules mediate association of SV40 with caveolae. Mol Biol Cell 1997; 8: 47-57.

[5] Anderson HA, Chen Y, Norkin LC. MHC class I molecules are enriched in caveolae but do not enter with simian virus 40 . J Gen Virol 1998; 79: 1469-77.

[6] Parton RG, Lindsay M. Exploitation of major histocompatibility complex class I molecules and caveolae by simian virus 40 . Immunol Rev 1999; 168: 23-31.

[7] Pelkmans L, Kartenbeck J, Helenius A. Caveolar endocytosis of simian virus 40 reveals a new two-step vesicular-transport pathway to the ER. Nat Cell Biol 2001; 3: 473-83.

[8] Norkin LC, Anderson HA, Wolfrom SA, Oppenheim A. Caveolar endocytosis of simian virus 40 is followed by brefeldin A-sensitive transport to the endoplasmic reticulum, where the virus disassembles. J Virol 2002; 76: 5156-66.

[9] Pelkmans L, Puntener D, Helenius A. Local actin polymerization and dynamin recruitment in SV40-induced internalization of caveolae. Science 2002; 296: 535-9.

[10] Tsai B, Gilbert JM, Stehle T, Lencer W, Benjamin TL, Rapoport TA. Gangliosides are receptors for murine polyoma virus and SV40. EMBO J 2003; 22: 4346-55.

[11] Gilbert J, Dahl J, Riney C, et al. Ganglioside GD1a restores infectibility to mouse cells lacking functional receptors for polyomavirus. J Virol 2005; 79: 615-8.

[12] Schelhaas M, Malmstrom J, Pelkmans L, et al. Simian Virus 40 depends on ER protein folding and quality control factors for entry into host cells. Cell 2007; 131: 516-29.

[13] Eash S, Querbes W, Atwood WJ. Infection of vero cells by BK virus is dependent on caveolae. J Virol 2004; 78: 11583-90.

[14] Eash S, Atwood WJ. Involvement of cytoskeletal components in BK virus infectious entry. J Virol 2005; 79: 11734-41.

[15] Moriyama T, Marquez JP, Wakatsuki T, Sorokin A. Caveolar endocytosis is critical for $\mathrm{BK}$ virus infection of human renal proximal tubular epithelial cells. J Virol 2007; 81: 8552-62.

[16] Querbes W, O'Hara BA, Williams G, Atwood WJ. Invasion of host cells by JC virus identifies a novel role for caveolae in endosomal sorting of noncaveolar ligands. J Virol 2006; 80: 9402-13.

[17] Laniosz V, Holthusen KA, Meneses PI. Bovine papillomavirus type 1: from clathrin to caveolin. J Virol 2008; 82: 6288-98.

[18] Lyman MG, Curanovic D, Enquist LW. Targeting of pseudorabies virus structural proteins to axons requires association of the viral Us9 protein with lipid rafts. PLoS Pathog 2008; 4: e1000065.

[19] Matsushima Y, Fukasawa H, Endo Y, Hashimoto Y, Shudo K. Enhancement of human papillomavirus type 18 gene expression in $\mathrm{HeLa}$ cells by 12-O-tetradecanoylphorbol-13-acetate, 3 beta,5 alpha-dihydroxycholestan-6-one, and cholesterol. Biol Pharm Bull 1994; 17: 1292-5.

[20] Selinka HC, Giroglou T, Sapp M. Analysis of the infectious entry pathway of human papillomavirus type 33 pseudovirions. Virology 2002; 299: 279-287.

[21] Bousarghin L, Touze A, Sizaret PY, Coursaget P. Human papillomavirus types 16, 31, and 58 use different endocytosis pathways to enter cells. J Virol 2003; 77: 3846-50.

[22] Hatta M, Nagai H, Okino K, et al. Down-regulation of members of glycolipid-enriched membrane raft gene family, MAL and BENE, in cervical squamous cell cancers. J Obstet Gynaecol Res 2004; 30: 53-8.

[23] Hindmarsh PL, Laimins LA. Mechanisms regulating expression of the HPV $31 \mathrm{~L} 1$ and L2 capsid proteins and pseudovirion entry. Virol J 2007; 4: 19.

[24] Smith JL, Campos SK, Ozbun MA. Human papillomavirus type 31 uses a caveolin 1- and dynamin 2-mediated entry pathway for infection of human keratinocytes. J Virol 2007; 81: 9922-31.

[25] Smith JL, Campos SK, Wandinger-Ness A, Ozbun MA. Caveolin1-dependent infectious entry of human papillomavirus type 31 in human keratinocytes proceeds to the endosomal pathway for $\mathrm{pH}$ dependent uncoating. J Virol 2008; 82: 9505-12.
[26] Spoden G, Freitag K, Husmann M, et al. Clathrin- and caveolinindependent entry of human papillomavirus type 16--involvement of tetraspanin-enriched microdomains (TEMs). PLoS one 2008; 3 : e3313.

[27] Guerrero CA, Zarate S, Corkidi G, Lopez S, Arias CF. Biochemical characterization of rotavirus receptors in MA104 cells. J Virol 2000; 74: 9362-71.

[28] Arias CF, Isa P, Guerrero CA, et al. Molecular biology of rotavirus cell entry. Arch Med Res 2002; 33: 356-61.

[29] Sapin C, Colard O, Delmas O, et al. Rafts promote assembly and atypical targeting of a nonenveloped virus, rotavirus, in Caco-2 cells. J Virol 2002; 76: 4591-602.

[30] Marjomaki V, Pietiainen V, Matilainen H, et al. Internalization of echovirus 1 in caveolae. J Virol 2002; 76: 1856-65.

[31] Stuart AD, Eustace HE, McKee TA, Brown TD. A novel cell entry pathway for a DAF-using human enterovirus is dependent on lipid rafts. J Virol 2002; 76: 9307-22.

[32] Pietiainen V, Marjomaki V, Upla P, Pelkmans L, Helenius A, Hyypia T. Echovirus 1 endocytosis into caveosomes requires lipid rafts, dynamin II, and signaling events. Mol Biol Cell 2004; 15: 4911-25.

[33] Upla P, Marjomaki V, Kankaanpaa P, et al. Clustering induces a lateral redistribution of alpha 2 beta 1 integrin from membrane rafts to caveolae and subsequent protein kinase C-dependent internalization. Mol Biol Cell 2004; 15: 625-36.

[34] Pietiainen VM, Marjomaki V, Heino J, Hyypia T. Viral entry, lipid rafts and caveosomes. Ann Med 2005; 37: 394-403.

[35] Karjalainen M, Kakkonen E, Upla P, et al. A raft-derived, Pak1regulated entry participates in alpha2beta 1 integrin-dependent sorting to caveosomes. Mol Biol Cell 2008; 19: 2857-69.

[36] Grassme H, Riehle A, Wilker B, Gulbins E. Rhinoviruses infect human epithelial cells via ceramide-enriched membrane platforms. J Biol Chem 2005; 280: 26256-62.

[37] Triantafilou K, Fradelizi D, Wilson K, Triantafilou M. GRP78, a coreceptor for coxsackievirus A9, interacts with major histocompatibility complex class I molecules which mediate virus internalization. J Virol 2002; 76: 633-43.

[38] Triantafilou K, Triantafilou M. Lipid raft microdomains: key sites for Coxsackievirus A9 infectious cycle. Virology 2003; 317: 12835.

[39] Triantafilou K, Triantafilou M. Lipid-raft-dependent Coxsackievirus B4 internalization and rapid targeting to the Golgi. Virology 2004; 326: 6-19.

[40] Colin M, Mailly L, Rogee S, D'Halluin JC. Efficient species C HAdV infectivity in plasmocytic cell lines using a clathrinindependent lipid raft/caveola endocytic route. Mol Ther 2005; 11 : 224-36.

[41] Rogee S, Grellier E, Bernard C, et al. Intracellular trafficking of a fiber-modified adenovirus using lipid raft/caveolae endocytosis. Mol Ther 2007; 15: 1963-72.

[42] Levine AJ. The common mechanisms of transformation by the small DNA tumor viruses: The inactivation of tumor suppressor gene products: p53. Virology 2009; 384: 285-93.

[43] Kurzchalia TV, Dupree P, Parton RG, et al. VIP21, a 21-kD membrane protein is an integral component of trans-Golginetwork-derived transport vesicles. J Cell Biol 1992; 118: 1003-14.

[44] Rothberg KG, Heuser JE, Donzell WC, Ying YS, Glenney JR, Anderson RG. Caveolin, a protein component of caveolae membrane coats. Cell 1992; 68: 673-82.

[45] Pelkmans L, Kartenbeck J, Helenius A. Caveolar endocytosis of simian virus 40 reveals a new two-step vesicular-transport pathway to the ER. Nat Cell Biol 2001; 3: 473-83.

[46] Pelkmans L, Puntener D, Helenius A. Local actin polymerization and dynamin recruitment in SV40-induced internalization of caveolae. Science 2002; 296: 535-9.

[47] Liebl D, Difato F, Hornikova L, Mannova P, Stokrova J, Forstova J. Mouse polyomavirus enters early endosomes, requires their acidic $\mathrm{pH}$ for productive infection, and meets transferrin cargo in Rab11-positive endosomes. J Virol 2006; 80: 4610-22.

[48] Hoots BE, Palefsky JM, Pimenta JM, Smith JS. Human papillomavirus type distribution in anal cancer and anal intraepithelial lesions. Int J Cancer 2008; 124: 2375-2383.

[49] Chu CL, Buczek-Thomas JA, Nugent MA. Heparan sulphate proteoglycans modulate fibroblast growth factor-2 binding through a lipid raft-mediated mechanism. Biochem J 2004; 379: 331-41. 
[50] Yang X, Kovalenko OV, Tang W, Claas C, Stipp CS, Hemler ME. Palmitoylation supports assembly and function of integrintetraspanin complexes. J Cell Biol 2004; 167: 1231-40.

[51] Israels SJ, McMillan-Ward EM. Platelet tetraspanin complexes and their association with lipid rafts. Thromb Haemost 2007 ;98: 10817.

[52] Greve JM, Davis G, Meyer AM, et al. The major human rhinovirus receptor is ICAM-1. Cell 1989; 56: 839-47.

[53] Staunton DE, Merluzzi VJ, Rothlein R, Barton R, Marlin SD, Springer TA. A cell adhesion molecule, ICAM-1, is the major surface receptor for rhinoviruses. Cell 1989; 56: 849-53.

[54] Bella J, Rossmann MG. ICAM-1 receptors and cold viruses. Pharm Acta Helv 2000; 74: 291-7.

[55] Bacso Z, Bene L, Damjanovich L, Damjanovich S. INF-gamma rearranges membrane topography of MHC-I and ICAM-1 in colon carcinoma cells. Biochem Biophys Res Commun 2002; 290: 63540.

[56] Dechecchi MC, Melotti P, Bonizzato A, Santacatterina M, Chilosi M, Cabrini G. Heparan sulfate glycosaminoglycans are receptors sufficient to mediate the initial binding of adenovirus types 2 and 5 . J Virol 2001; 75: 8772-80.

[57] Cleverley DZ, Geller HM, Lenard J. Characterization of cholesterol-free insect cells infectible by baculoviruses: effects of cholesterol on VSV fusion and infectivity and on cytotoxicity induced by influenza M2 protein. Exp Cell Res 1997; 233: 288-96.

[58] Sieczkarski SB, Whittaker GR. Influenza virus can enter and infect cells in the absence of clathrin-mediated endocytosis. J Virol 2002; 76: $10455-64$

[59] Takeda M, Leser GP, Russell CJ, Lamb RA. Influenza virus hemagglutinin concentrates in lipid raft microdomains for efficient viral fusion. Proc Natl Acad Sci USA 2003; 100: 14610-7.

[60] Lakadamyali M, Rust MJ, Zhuang X. Endocytosis of influenza viruses. Microbes Infect 2004; 6: 929-36.

[61] Smith AE, Helenius A. How viruses enter animal cells. Science 2004; 304: 237-42.

[62] Manes S, del Real G, Lacalle RA, et al. Membrane raft microdomains mediate lateral assemblies required for HIV-1 infection. EMBO Rep 2000; 1: 190-6.

[63] Campbell SM, Crowe SM, Mak J. Lipid rafts and HIV-1: from viral entry to assembly of progeny virions. J Clin Virol 2001; 22: 217-27.

[64] Liao Z, Graham DR, Hildreth JE. Lipid rafts and HIV pathogenesis: virion-associated cholesterol is required for fusion and infection of susceptible cells. AIDS Res Hum Retroviruses 2003; 19: 675-87.

[65] Huarte N, Lorizate M, Kunert R, Nieva JL. Lipid modulation of membrane-bound epitope recognition and blocking by HIV-1 neutralizing antibodies. FEBS Lett 2008; 582: 3798-804.

[66] Carter GC, Bernstone L, Sangani D, Bee JW, Harder T, James W. HIV entry in macrophages is dependent on intact lipid rafts. Virology 2009; 386: 192-202.

[67] Kamiyama H, Yoshii H, Tanaka Y, Sato H, Yamamoto N, Kubo Y. Raft localization of CXCR4 is primarily required for X4-tropic human immunodeficiency virus type 1 infection. Virology 2009; 386: 23-31.

[68] Niyogi K, Hildreth JE. Characterization of new syncytiuminhibiting monoclonal antibodies implicates lipid rafts in human Tcell leukemia virus type 1 syncytium formation. J Virol 2001; 75: 7351-61.

[69] Wielgosz MM, Rauch DA, Jones KS, Ruscetti FW, Ratner L. Cholesterol dependence of HTLV-I infection. AIDS Res Hum Retroviruses 2005; 21: 43-50.

[70] Bavari S, Bosio CM, Wiegand E, et al. Lipid raft microdomains: a gateway for compartmentalized trafficking of Ebola and Marburg viruses. J Exp Med 2002; 195: 593-602.

[71] Aman MJ, Bosio CM, Panchal RG, Burnett JC, Schmaljohn A, Bavari S. Molecular mechanisms of filovirus cellular trafficking. Microbes Infect 2003; 5: 639-49.

[72] Fingeroth JD, Weis JJ, Tedder TF, Strominger JL, Biro PA, Fearon DT. Epstein-Barr virus receptor of human B lymphocytes is the C3d receptor CR2. Proc Natl Acad Sci USA 1984; 81: 4510-4.

[73] Cherukuri A, Carter RH, Brooks $\mathrm{S}$, et al. B cell signaling is regulated by induced palmitoylation of CD81. J Biol Chem 2004; 279: 31973-82.
[74] Bender FC, Whitbeck JC, Ponce de Leon M, Lou H, Eisenberg RJ, Cohen GH. Specific association of glycoprotein B with lipid rafts during herpes simplex virus entry. J Virol 2003; 77: 9542-52.

[75] Desplanques AS, Nauwynck HJ, Vercauteren D, Geens T, Favoreel HW. Plasma membrane cholesterol is required for efficient pseudorabies virus entry. Virology 2008; 376: 339-45.

[76] Tang H, Kawabata A, Takemoto M, Yamanishi K, Mori Y. Human herpesvirus- 6 infection induces the reorganization of membrane microdomains in target cells, which are required for virus entry. Virology 2008; 378: 265-71

[77] Raghu H, Sharma-Walia N, Veettil MV, et al. Lipid rafts of primary endothelial cells are essential for Kaposi's sarcomaassociated herpesvirus/human herpesvirus 8-induced phosphatidylinositol 3-kinase and RhoA-GTPases critical for microtubule dynamics and nuclear delivery of viral DNA but dispensable for binding and entry. J Virol 2007; 81: 7941-59.

[78] Chung CS, Huang CY, Chang W. Vaccinia virus penetration requires cholesterol and results in specific viral envelope proteins associated with lipid rafts. J Virol 2005; 79: 1623-34.

[79] Nomura R, Kiyota A, Suzaki E, et al. Human coronavirus 229E binds to CD13 in rafts and enters the cell through caveolae. J Virol 2004; 78: 8701-8.

[80] Thorp EB, Gallagher TM. Requirements for CEACAMs and cholesterol during murine coronavirus cell entry. J Virol 2004; 78: 2682-92.

[81] Choi KS, Aizaki H, Lai MM. Murine coronavirus requires lipid rafts for virus entry and cell-cell fusion but not for virus release. J Virol 2005; 79: 9862-71.

[82] Li GM, Li YG, Yamate M, Li SM, Ikuta K. Lipid rafts play an important role in the early stage of severe acute respiratory syndrome-coronavirus life cycle. Microbes Infect 2007; 9: 96-102.

[83] Wang H, Yang P, Liu K, et al. SARS coronavirus entry into host cells through a novel clathrin- and caveolae-independent endocytic pathway. Cell Res 2008; 18: 290-301.

[84] Lu Y, Liu DX, Tam JP. Lipid rafts are involved in SARS-CoV entry into Vero E6 cells. Biochem Biophys Res Commun 2008; 369: 344-9.

[85] Van Hamme E, Dewerchin HL, Cornelissen E, Verhasselt B, Nauwynck HJ. Clathrin- and caveolae-independent entry of feline infectious peritonitis virus in monocytes depends on dynamin. $\mathrm{J}$ Gen Virol 2008; 89: 2147-56.

[86] Medigeshi GR, Hirsch AJ, Streblow DN, Nikolich-Zugich J, Nelson JA. West Nile virus entry requires cholesterol-rich membrane microdomains and is independent of alphavbeta3 integrin. J Virol 2008; 82: 5212-9.

[87] Lee CJ, Liao CL, Lin YL. Flavivirus activates phosphatidylinositol 3-kinase signaling to block caspase-dependent apoptotic cell death at the early stage of virus infection. J Virol 2005; 79: 8388-99.

[88] Reyes-Del Valle J, Cha'vez-Salinas S, Medina F, Del Angel RM. Heat shock protein 90 and heat shock protein 70 are components of dengue virus receptor complex in human cells. J Virol 2005; 79: 4557-67.

[89] Lee CJ, Lin HR, Liao CL, Lin YL. Cholesterol effectively blocks entry of flavivirus. J Virol 2008; 82: 6470-80.

[90] Kapadia SB, Barth H, Baumert T, McKeating JA, Chisari FV Initiation of hepatitis $\mathrm{C}$ virus infection is dependent on cholesterol and cooperativity between CD81 and scavenger receptor B type I. J Virol 2007; 81: 374-83.

[91] Voisset C, Lavie M, Helle F, et al. Ceramide enrichment of the plasma membrane induces CD81 internalization and inhibits hepatitis C virus entry. Cell Microbiol 2008; 10: 606-17.

[92] Kielian MC, Helenius A. Role of cholesterol in fusion of Semliki Forest virus with membranes. J Virol 1984; 52: 281-3.

[93] Phalen T, Kielian M. Cholesterol is required for infection by Semliki Forest virus. J Cell Biol 1991; 112: 615-23.

[94] Ahn A, Gibbons DL, Kielian M. The fusion peptide of Semliki Forest virus associates with sterol-rich membrane domains. J Virol 2002; 76: 3267-75.

[95] Waarts BL, Bittman R, Wilschut J. Sphingolipid and cholesterol dependence of alphavirus membrane fusion. Lack of correlation with lipid raft formation in target liposomes. J Biol Chem 2002; 277: 38141-7.

[96] Lu YE, Cassese T, Kielian M. The cholesterol requirement for sindbis virus entry and exit and characterization of a spike protein region involved in cholesterol dependence. J Virol 1999; 73: 42728. 
[97] Quirin K, Eschli B, Scheu I, Poort L, Kartenbeck J, Helenius A. Lymphocytic choriomeningitis virus uses a novel endocytic pathway for infectious entry via late endosomes. Virology 2008; 378: 21-33.

[98] Naslavsky N, Stein R, Yanai A, Friedlander G, Taraboulos A. Characterization of detergent-insoluble complexes containing the cellular prion protein and its scrapie isoform. J Biol Chem 1997; 272: 6324-31.

[99] Sarnataro D, Campana V, Paladino S, Stornaiuolo M, Nitsch L, Zurzolo C. $\operatorname{Pr} \mathrm{P}(\mathrm{C})$ association with lipid rafts in the early secretory pathway stabilizes its cellular conformation. Mol Biol Cell 2004; 15: 4031-42.

[100] Gilch S, Kehler C, Schatzl HM. The prion protein requires cholesterol for cell surface localization. Mol Cell Neurosci 2006; 31: 346-53.

[101] Avrahami D, Dayan-Amouyal Y, Tal S, et al. Virus-induced alterations of membrane lipids affect the incorporation of PrP Sc into cells. J Neurosci Res 2008; 86: 2753-62.

[102] Suzuki Y, Ito T, Suzuki T, et al. Sialic acid species as a determinant of the host range of influenza A viruses. J Virol 2000; 74: $11825-31$

[103] Suzuki Y, Nagao Y, Kato H, et al. Human influenza A virus hemagglutinin distinguishes sialyloligosaccharides in membraneassociated gangliosides as its receptor which mediates the adsorption and fusion processes of virus infection. Specificity for oligosaccharides and sialic acids and the sequence to which sialic acid is attached. J Biol Chem 1986; 261: 17057-61.

[104] Schroeder C, Heider H, Moncke-Buchner E, Lin TI. The influenza virus ion channel and maturation cofactor M2 is a cholesterolbinding protein. Eur Biophys J 2005; 34: 52-66.

[105] Cooper A, Shaul Y. Clathrin-mediated endocytosis and lysosomal cleavage of hepatitis B virus capsid-like core particles. J Biol Chem 2006; 281 : $16563-9$

[106] Deng H, Liu R, Ellmeier W, et al. Identification of a major coreceptor for primary isolates of HIV-1. Nature 1996; 381: 661-6.

[107] Dragic T, Litwin V, Allaway GP, et al. HIV-1 entry into CD4+ cells is mediated by the chemokine receptor CC-CKR-5. Nature 1996; 381: 667-73.

[108] Briggs DR, Tuttle DL, Sleasman JW, Goodenow MM. Envelope V3 amino acid sequence predicts HIV-1 phenotype (co-receptor usage and tropism for macrophages). AIDS 2000; 14: 2937-9.

[109] Manes S, Mira E, Gomez-Mouton C, et al. Membrane raft microdomains mediate front-rear polarity in migrating cells. EMBO J 1999; 18: 6211-20.

[110] Kozak SL, Heard JM, Kabat D. Segregation of CD4 and CXCR4 into distinct lipid microdomains in $\mathrm{T}$ lymphocytes suggests a mechanism for membrane destabilization by human immunodeficiency virus. J Virol 2002; 76: 1802-15.

[111] Gaibelet G, Planchenault T, Mazeres S, et al. CD4 and CCR5 constitutively interact at the plasma membrane of living cells: a confocal fluorescence resonance energy transfer-based approach. J Biol Chem 2006; 281: 37921-9.

[112] Fantini J, Cook DG, Nathanson N, Spitalnik SL, Gonzalez-Scarano F. Infection of colonic epithelial cell lines by type 1 human immunodeficiency virus is associated with cell surface expression of galactosylceramide, a potential alternative gp120 receptor. Proc Natl Acad Sci USA 1993; 90: 2700-4.

[113] Hammache D, Pieroni G, Yahi N, et al. Specific interaction of HIV-1 and HIV-2 surface envelope glycoproteins with monolayers of galactosylceramide and ganglioside GM3. J Biol Chem 1998; 273: 7967-71.

[114] Puri A, Hug P, Jernigan K, et al. The neutral glycosphingolipid globotriaosylceramide promotes fusion mediated by a CD4dependent CXCR4-utilizing HIV type 1 envelope glycoprotein. Proc Natl Acad Sci USA 1998; 95: 14435-40.

[115] Rawat SS, Viard M, Gallo SA, Blumenthal R, Puri A. Sphingolipids, cholesterol, and HIV-1: a paradigm in viral fusion. Glycoconj J 2006; 23: 189-97.

[116] Argyris EG, Acheampong E, Nunnari G, Mukhtar M, Williams KJ, Pomerantz RJ. Human immunodeficiency virus type 1 enters primary human brain microvascular endothelial cells by a mechanism involving cell surface proteoglycans independent of lipid rafts. J Virol 2003; 77: 12140-51.

[117] Manel N, Kim FJ, Kinet S, Taylor N, Sitbon M, Battini JL. The ubiquitous glucose transporter GLUT-1 is a receptor for HTLV. Cell 2003; 115: 449-59.
[118] Kumar A, Xiao YP, Laipis PJ, Fletcher BS, Frost SC. Glucose deprivation enhances targeting of GLUT1 to lipid rafts in 3T3-L1 adipocytes. Am J Physiol Endocrinol Metab 2004; 286: E568-76.

[119] Nichols BJ, Kenworthy AK, Polishchuk RS, et al. Rapid cycling of lipid raft markers between the cell surface and Golgi complex. J Cell Biol 2001; 153: 529-41

[120] Chan SY, Speck RF, Ma MC, Goldsmith MA. Distinct mechanisms of entry by envelope glycoproteins of Marburg and Ebola (Zaire) viruses. J Virol 2000; 74: 4933-7.

[121] Wool-Lewis RJ, Bates P. Characterization of Ebola virus entry by using pseudotyped viruses: identification of receptor-deficient cell lines. J Virol 1998; 72: 3155-60.

[122] Birkenbach M, Tong X, Bradbury LE, Tedder TF, Kieff E. Characterization of an Epstein-Barr virus receptor on human epithelial cells. J Exp Med 1992; 176: 1405-14.

[123] Montgomery RI, Warner MS, Lum BJ, Spear PG. Herpes simplex virus-1 entry into cells mediated by a novel member of the TNF/NGF receptor family. Cell 1996; 87: 427-36.

[124] Geraghty RJ, Krummenacher C, Cohen GH, Eisenberg RJ, Spear PG. Entry of alphaherpesviruses mediated by poliovirus receptorrelated protein 1 and poliovirus receptor. Science 1998; 280: 161820

[125] Satoh T, Arii J, Suenaga T, et al. PILRalpha is a herpes simplex virus-1 entry coreceptor that associates with glycoprotein B. Cell 2008; 132: 935-44.

[126] Shukla D, Liu J, Blaiklock P, et al. A novel role for 3-O-sulfated heparan sulfate in herpes simplex virus 1 entry. Cell 1999; 99: 1322

[127] Bender FC, Whitbeck JC, Lou H, Cohen GH, Eisenberg RJ. Herpes simplex virus glycoprotein B binds to cell surfaces independently of heparan sulfate and blocks virus entry. J Virol 2005; 79: 1158897.

[128] Legler DF, Micheau O, Doucey MA, Tschopp J, Bron C. Recruitment of TNF receptor 1 to lipid rafts is essential for TNFalpha-mediated NF-kappaB activation. Immunity 2003; 18: 655-64.

[129] Chu JJ, Ng ML. Interaction of West Nile virus with alpha $v$ beta 3 integrin mediates virus entry into cells. J Biol Chem 2004; 279: 54533-41.

[130] Chu JJ, Ng ML. Infectious entry of West Nile virus occurs through a clathrin-mediated endocytic pathway. J Virol 2004; 78: 10543-55.

[131] Navarro-Sanchez E, Altmeyer R, Amara A, et al. Dendritic-cellspecific ICAM3-grabbing non-integrin is essential for the productive infection of human dendritic cells by mosquito-cellderived dengue viruses. EMBO Rep 2003; 4: 723-8.

[132] Chen Y, Maguire T, Hileman RE, et al. Dengue virus infectivity depends on envelope protein binding to target cell heparan sulfate. Nat Med 1997; 3: 866-71.

[133] Aoki C, Hidari KI, Itonori $\mathrm{S}$, et al. Identification and characterization of carbohydrate molecules in mammalian cells recognized by dengue virus type 2. J Biochem 2006; 139: 607-14.

[134] Caparros E, Munoz P, Sierra-Filardi E, et al. DC-SIGN ligation on dendritic cells results in ERK and PI $3 \mathrm{~K}$ activation and modulates cytokine production. Blood 2006; 107: 3950-8.

[135] Das S, Laxminarayana SV, Chandra N, Ravi V, Desai A. Heat shock protein 70 on Neuro2a cells is a putative receptor for Japanese encephalitis virus. Virology 2009; 385: 47-57.

[136] Chien YJ, Chen WJ, Hsu WL, Chiou SS. Bovine lactoferrin inhibits Japanese encephalitis virus by binding to heparan sulfate and receptor for low density lipoprotein. Virology 2008; 379: 143 51 .

[137] Umashankar M, Sanchez-San Martin C, Liao M, et al. Differential cholesterol binding by class II fusion proteins determines membrane fusion properties. J Virol 2008; 82: 9245-53.

[138] Cuadras MA, Greenberg HB. Rotavirus infectious particles use lipid rafts during replication for transport to the cell surface in vitro and in vivo. Virology 2003; 313: 308-21.

[139] Delmas O, Durand-Schneider AM, Cohen J, Colard O, Trugnan G. Spike protein VP4 assembly with maturing rotavirus requires a postendoplasmic reticulum event in polarized caco-2 cells. J Virol. 2004: 10987-94

[140] Delmas O, Breton M, Sapin C, Le Bivic A, Colard O, Trugnan G. Heterogeneity of raft-type membrane microdomains associated with VP4, the rotavirus spike protein, in Caco-2 and MA 104 cells. J Virol 2007; 81: 1610-8. 
[141] Storey SM, Gibbons TF, Williams CV, Parr RD, Schroeder F, Ball JM. Full-length, glycosylated NSP4 is localized to plasma membrane caveolae by a novel raft isolation technique. J Virol. 2007; 81: 5472-83.

[142] Bhattacharya B, Roy P. Bluetongue virus outer capsid protein VP5 interacts with membrane lipid rafts via a SNARE domain. J Virol 2008; 82: 10600-12.

[143] Shi ST, Lee KJ, Aizaki H, Hwang SB, Lai MM. Hepatitis C virus RNA replication occurs on a detergent-resistant membrane that cofractionates with caveolin-2. J Virol 2003; 77: 4160-8.

[144] Aizaki H, Lee KJ, Sung VM, Ishiko H, Lai MM. Characterization of the hepatitis $\mathrm{C}$ virus RNA replication complex associated with lipid rafts. Virology 2004; 324: 450-61.

[145] Sakamoto H, Okamoto K, Aoki M, et al. Host sphingolipid biosynthesis as a target for hepatitis $\mathrm{C}$ virus therapy. Nat Chem Biol 2005; 1: 333-7.

[146] Aizaki H, Morikawa K, Fukasawa M, et al. Critical role of virionassociated cholesterol and sphingolipid in hepatitis $\mathrm{C}$ virus infection. J Virol 2008; 82: 5715-24.

[147] McDonald TP, Pitt AR, Brown G, Rixon HW, Sugrue RJ. Evidence that the respiratory syncytial virus polymerase complex associates with lipid rafts in virus-infected cells: a proteomic analysis. Virology 2004; 330: 147-57.

[148] Brown G, Rixon HW, Steel J, et al. Evidence for an association between heat shock protein 70 and the respiratory syncytial virus polymerase complex within lipid-raft membranes during virus infection. Virology 2005; 338: 69-80.

[149] Noisakran S, Dechtawewat T, Avirutnan P, et al. Association of dengue virus NS1 protein with lipid rafts. J Gen Virol 2008; 89: 2492-500.

[150] Keller P, Simons K. Cholesterol is required for surface transport of influenza virus hemagglutinin. J Cell Biol 1998; 140: 1357-67.

[151] Scheiffele P, Rietveld A, Wilk T, Simons K. Influenza viruses select ordered lipid domains during budding from the plasma membrane. J Biol Chem 1999; 274: 2038-44.

[152] Barman S, Nayak DP. Analysis of the transmembrane domain of influenza virus neuraminidase, a type II transmembrane glycoprotein, for apical sorting and raft association. J Virol 2000; 74: $6538-45$

[153] Heino S, Lusa S, Somerharju P, Ehnholm C, Olkkonen VM, Ikonen E. Dissecting the role of the golgi complex and lipid rafts in biosynthetic transport of cholesterol to the cell surface. Proc Natl Acad Sci USA 2000; 97: 8375-80.

[154] Zhang J, Pekosz A, Lamb RA. Influenza virus assembly and lipid raft microdomains: a role for the cytoplasmic tails of the spike glycoproteins. J Virol 2000; 74: 4634-44.

[155] Barman S, Adhikary L, Chakrabarti AK, Bernas C, Kawaoka Y, Nayak DP. Role of transmembrane domain and cytoplasmic tail amino acid sequences of influenza A virus neuraminidase in raft association and virus budding. J Virol 2004; 78: 5258-69.

[156] Carrasco M, Amorim MJ, Digard P. Lipid raft-dependent targeting of the influenza A virus nucleoprotein to the apical plasma membrane. Traffic 2004; 5: 979-92.

[157] Leser GP, Lamb RA. Influenza virus assembly and budding in raftderived microdomains: A quantitative analysis of the surface distribution of HA, NA and M2 proteins. Virology 2005; 342: 21527.

[158] Marjuki H, Alam MI, Ehrhardt C, et al. Membrane accumulation of influenza A virus hemagglutinin triggers nuclear export of the viral genome via protein kinase $\mathrm{C}$ alpha-mediated activation of ERK signaling. J Biol Chem 2006; 281: 16707-15.

[159] Chen BJ, Leser GP, Morita E, Lamb RA. Influenza virus hemagglutinin and neuraminidase, but not the matrix protein, are required for assembly and budding of plasmid-derived virus-like particles. J Virol 2007; 81: 7111-23.

[160] Barman S, Nayak DP. Lipid raft disruption by cholesterol depletion enhances influenza A virus budding from MDCK cells. J Virol 2007; 81: 12169-78.

[161] Nguyen DH, Hildreth JE. Evidence for budding of human immunodeficiency virus type 1 selectively from glycolipidenriched membrane lipid rafts. J Virol 2000; 74: 3264-72.

[162] Welker R, Harris M, Cardel B, Krausslich HG. Virion incorporation of human immunodeficiency virus type 1 Nef is mediated by a bipartite membrane-targeting signal: analysis of its role in enhancement of viral infectivity. J Virol 1998; 72: 8833-40.
[163] Wang JK, Kiyokawa E, Verdin E, Trono D. The Nef protein of HIV-1 associates with rafts and primes T cells for activation. Proc Natl Acad Sci USA 2000; 97: 394-9.

[164] Wyma DJ, Kotov A, Aiken C. Evidence for a stable interaction of gp41 with Pr55(Gag) in immature human immunodeficiency virus type 1 particles. J Virol 2000; 74: 9381-7.

[165] Lindwasser OW, Resh MD. Multimerization of human immunodeficiency virus type $1 \mathrm{Gag}$ promotes its localization to barges, raft-like membrane microdomains. J Virol 2001; 75: 791324.

[166] Zheng YH, Plemenitas A, Linnemann T, Fackler OT, Peterlin BM. Nef increases infectivity of HIV via lipid rafts. Curr Biol 2001; 11: 875-9.

[167] Ono A, Freed EO. Plasma membrane rafts play a critical role in HIV-1 assembly and release. Proc Natl Acad Sci USA 2001; 98 : 13925-30.

[168] Bhattacharya J, Peters PJ, Clapham PR. Human immunodeficiency virus type 1 envelope glycoproteins that lack cytoplasmic domain cysteines: impact on association with membrane lipid rafts and incorporation onto budding virus particles. J Virol 2004; 78: 55006.

[169] Ono A, Waheed AA, Joshi A, Freed EO. Association of human immunodeficiency virus type 1 gag with membrane does not require highly basic sequences in the nucleocapsid: use of a novel Gag multimerization assay. J Virol 2005; 79: 14131-40.

[170] Giese SI, Woerz I, Homann S, Tibroni N, Geyer M, Fackler OT. Specific and distinct determinants mediate membrane binding and lipid raft incorporation of HIV-1(SF2) Nef. Virology 2006; 355: 175-91.

[171] Brugger B, Krautkramer E, Tibroni N, et al. Human immunodeficiency virus type 1 Nef protein modulates the lipid composition of virions and host cell membrane microdomains. Retrovirology 2007; 4: 70 .

[172] Ono A, Waheed AA, Freed EO. Depletion of cellular cholesterol inhibits membrane binding and higher-order multimerization of human immunodeficiency virus type $1 \mathrm{Gag}$. Virology 2007; 360: 27-35.

[173] Leung K, Kim JO, Ganesh L, Kabat J, Schwartz O, Nabel GJ. HIV1 assembly: viral glycoproteins segregate quantally to lipid rafts that associate individually with HIV-1 capsids and virions. Cell Host Microbe 2008; 3: 285-92.

[174] Feng X, Heyden NV, Ratner L. Alpha interferon inhibits human Tcell leukemia virus type 1 assembly by preventing Gag interaction with rafts. J Virol 2003; 77: 13389-95.

[175] Manie SN, de Breyne S, Vincent S, Gerlier D. Measles virus structural components are enriched into lipid raft microdomains: a potential cellular location for virus assembly. J Virol 2003; 77: 13389-95.

[176] Vincent S, Gerlier D, Manie SN. Measles virus assembly within membrane rafts. J Virol 2000; 74: 9911-5.

[177] Ali A, Nayak DP. Assembly of Sendai virus: M protein interacts with $\mathrm{F}$ and $\mathrm{HN}$ proteins and with the cytoplasmic tail and transmembrane domain of F protein. Virology 2000; 276: 289-303.

[178] Gosselin-Grenet AS, Mottet-Osman G, Roux L. From assembly to virus particle budding: pertinence of the detergent resistant membranes. Virology 2006; 344: 296-303.

[179] Laliberte JP, McGinnes LW, Peeples ME, Morrison TG. Integrity of membrane lipid rafts is necessary for the ordered assembly and release of infectious Newcastle disease virus particles. J Virol 2006; 80: 10652-62.

[180] Laliberte JP, McGinnes LW, Morrison TG. Incorporation of functional HN-F glycoprotein-containing complexes into Newcastle disease virus is dependent on cholesterol and membrane lipid raft integrity. J Virol 2007; 81: 10636-48.

[181] Brown G, Rixon HW, Sugrue RJ. Respiratory syncytial virus assembly occurs in GM1-rich regions of the host-cell membrane and alters the cellular distribution of tyrosine phosphorylated caveolin-1. J Gen Virol 2002; 83: 1841-50.

[182] Marty A, Meanger J, Mills J, Shields B, Ghildyal R. Association of matrix protein of respiratory syncytial virus with the host cell membrane of infected cells. Arch Virol 2004; 149: 199-210.

[183] Oomens AG, Bevis KP, Wertz GW. The cytoplasmic tail of the human respiratory syncytial virus $F$ protein plays critical roles in cellular localization of the $\mathrm{F}$ protein and infectious progeny production. J Virol 2006; 80: 10465-77. 
[184] Yeo DS, Chan R, Brown G, et al. Evidence that selective changes in the lipid composition of raft-membranes occur during respiratory syncytial virus infection. Virology 2009: 386; 168-82.

[185] Lee GE, Church GA, Wilson DW. A subpopulation of tegument protein vhs localizes to detergent-insoluble lipid rafts in herpes simplex virus-infected cells. J Virol 2003; 77: 2038-45.

[186] Koshizuka T, Kawaguchi Y, Nozawa N, Mori I, Nishiyama Y. Herpes simplex virus protein UL11 but not UL51 is associated with lipid rafts. Virus Genes 2007; 35: 571-5.

[187] Sharp EL, Davis-Poynter NJ, Farrell HE. Analysis of the subcellular trafficking properties of murine cytomegalovirus M78, a 7 transmembrane receptor homologue. J Gen Virol 2009; 90: 5968.

[188] Panchal RG, Ruthel G, Kenny TA, et al. In vivo oligomerization and raft localization of Ebola virus protein VP40 during vesicular budding. Proc Natl Acad Sci USA 2003; 100: 15936-41.

[189] Odenwald WF, Arnheiter H, Dubois-Dalcq M, Lazzarini RA. Stereo images of vesicular stomatitis virus assembly. J Virol 1986; 57: 922-32.

[190] Brown EL, Lyles DS. A novel method for analysis of membrane microdomains: vesicular stomatitis virus glycoprotein microdomains change in size during infection, and those outside of budding sites resemble sites of virus budding. Virology 2003; 310: 343-58.

[191] Sugrue RJ, Belshe RB, Hay AJ. Palmitoylation of the influenza A virus M2 protein. Virology 1990; 179: 51-6.

[192] Cheong KH, Zacchetti D, Schneeberger EE, Simons K. VIP17/MAL, a lipid raft-associated protein, is involved in apical transport in MDCK cells. Proc Natl Acad Sci USA 1999; 96: 62418.

[193] Chen BJ, Leser GP, Jackson D, Lamb RA. The influenza virus M2 protein cytoplasmic tail interacts with the M1 protein and influences virus assembly at the site of virus budding. J Virol 2008; 82: 10059-70.

[194] Mena I, Vivo A, Pe'rez E, Portela A. Rescue of a synthetic chloramphenicol acetyltransferase RNA into influenza virus-like particles obtained from recombinant plasmids. J Virol 1996; 70: 5016-24.

[195] Gomez-Puertas P, Albo C, Perez-Pastrana E, Vivo A, Portela A. Influenza virus matrix protein is the major driving force in virus budding. J Virol 2000; 74: 11538-47.

[196] Matrosovich M, Suzuki T, Hirabayashi Y, Garten W, Webster RG, Klenk HD. Gangliosides are not essential for influenza virus infection. Glycoconj J 2006; 23: 107-13.

[197] Takahashi T, Murakami K, Nagakura M, et al. Sulfatide is required for efficient replication of influenza A virus. J Virol 2008; 82: 5940-50.

[198] Arvanitis DN, Min W, Gong Y, Heng YM, Boggs JM. Two types of detergent-insoluble, glycosphingolipid/cholesterol-rich membrane domains from isolated myelin. J Neurochem 2005; 94: 1696-710.

[199] Lingwood D, Harauz G, Ballantyne JS. Regulation of fish gill $\mathrm{Na}(+)-\mathrm{K}(+)$-ATPase by selective sulfatide-enriched raft partitioning during seawater adaptation. J Biol Chem 2005; 280: 36545-50.

[200] Lindwasser OW, Resh MD. Myristoylation as a target for inhibiting HIV assembly: unsaturated fatty acids block viral budding. Proc Natl Acad Sci USA 2002; 99: 13037-42.

[201] Caballero M, Carabana J, Ortego J, Fernandez-Munoz R, Celma ML. Measles virus fusion protein is palmitoylated on transmembrane-intracytoplasmic cysteine residues which participate in cell fusion. J Virol 1998; 72: 8198-204.

[202] Mulari MT, Nars M, Laitala-Leinonen T, et al. Recombinant VSV $\mathrm{G}$ proteins reveal a novel raft-dependent endocytic pathway in resorbing osteoclasts. Exp Cell Res 2008; 314: 1641-51.

[203] Bentley JK, Newcomb DC, Goldsmith AM, Jia Y, Sajjan US, Hershenson MB. Rhinovirus activates interleukin-8 expression via a Src/p110beta phosphatidylinositol 3-kinase/Akt pathway in human airway epithelial cells. J Virol 2007; 81: 1186-94.

[204] Lee CJ, Liao CL, Lin YL. Flavivirus activates phosphatidylinositol 3-kinase signaling to block caspase-dependent apoptotic cell death at the early stage of virus infection. J Virol 2005; 79: 8388-99.

[205] Ghannam A, Hammache D, Matias C, Louwagie M, Garin J, Gerlier D. High-density rafts preferentially host the complement activator measles virus $\mathrm{F}$ glycoprotein but not the regulators of complement activation. Mol Immunol 2008; 45: 3036-44.

[206] Avota E, Muller N, Klett M, Schneider-Schaulies S. Measles virus interacts with and alters signal transduction in T-cell lipid rafts. J Virol 2004; 78: 9552-9.

[207] Min CK, Bang SY, Cho BA, et al. Role of amphipathic helix of a herpesviral protein in membrane deformation and $\mathrm{T}$ cell receptor downregulation. PLoS Pathog 2008; 4: e1000209.

[208] Howie HL, Katzenellenbogen RA, Galloway DA. Papillomavirus E6 proteins. Virology 2009; 384: 324-34.

[209] Suprynowicz FA, Disbrow GL, Krawczyk E, Simic V, Lantzky K, Schlegel R. HPV-16 E5 oncoprotein upregulates lipid raft components caveolin-1 and ganglioside GM1 at the plasma membrane of cervical cells. Oncogene 2008; 27: 1071-8.

[210] Moore ML, Chi MH, Goleniewska K, Durbin JE, Peebles RS Jr Differential regulation of GM1 and asialo-GM1 expression by $\mathrm{T}$ cells and natural killer (NK) cells in respiratory syncytial virus infection. Viral Immunol 2008; 21: 327-39.

[211] Hill JM, Steiner I, Matthews KE, Trahan SG, Foster TP, Ball MJ. Statins lower the risk of developing Alzheimer's disease by limiting lipid raft endocytosis and decreasing the neuronal spread of Herpes simplex virus type 1. Med Hypotheses 2005; 64: 53-8.

[212] Carter CJ. Interactions between the products of the Herpes simplex genome and Alzheimer's disease susceptibility genes: relevance to pathological-signalling cascades. Neurochem Int 2008; 52: 920-34.

[213] Ebihara T, Shingai M, Matsumoto M, Wakita T, Seya T. Hepatitis $\mathrm{C}$ virus-infected hepatocytes extrinsically modulate dendritic cell maturation to activate $\mathrm{T}$ cells and natural killer cells. Hepatology 2008; 48: 48-58

(C) Takahashi and Suzuki; Licensee Bentham Open.

This is an open access article licensed under the terms of the Creative Commons Attribution Non-Commercial License (http://creativecommons.org/licenses/by-nc/ $3.0 /$ ) which permits unrestricted, non-commercial use, distribution and reproduction in any medium, provided the work is properly cited. 